\title{
A Bidirectional Hybrid WDM-OFDM Network for Multiservice Communication Employing Self- Injection Locked Qdash Laser Source Based on Elimination of Rayleigh Backscattering Noise Technique
}

\section{Paulomi Mandal}

Sidho-Kanho-Birsha University

Khaleda Mallick

Sidho-Kanho-Birsha University

Saikat Santra

Sidho-Kanho-Birsha University

Bibhatsu Kuiri

Sidho-Kanho-Birsha University

\section{Bubai Dutta}

Sidho-Kanho-Birsha University

Ardhendu Sekhar Patra ( $\square$ ardhendu4u@yahoo.com )

Sidho-Kanho-Birsha University https://orcid.org/0000-0001-8416-7219

\section{Research Article}

Keywords: Rayleigh backscattering, self-injection locked Qdash laser, WDM-OFDM network

Posted Date: February 19th, 2021

DOI: https://doi.org/10.21203/rs.3.rs-213334/v1

License: (c) (i) This work is licensed under a Creative Commons Attribution 4.0 International License. Read Full License 
A Bidirectional Hybrid WDM-OFDM Network for Multiservice Communication Employing Self-Injection Locked Qdash Laser Source based on Elimination of Rayleigh Backscattering Noise Technique

Paulomi Mandal, Khaleda Mallick, Saikat Santra, Bibhatsu Kuiri, Bubai Dutta and Ardhendu Sekhar Patra*

Department of Physics, Sidho-Kanho-Birsha University, Purulia, India-723104 Address all correspondence to: Ardhendu Sekhar Patra, Dept. of Physics, Sidho-KanhoBirsha University, Purulia, West Bengal, India -723104. E-mail: ardhendu4u@yahoo.com; Telephone: +919433963530 


\begin{abstract}
:
A scheme for transportation of information with minimum Rayleigh backscattering (RB) noise to the multi-users by employing Qdash laser diode as a source is designed and evaluated. In this paper, employing DPSK, MMW, 16-QAM OFDM, and 32-QAM OFDM techniques, the data rates of 4X10 Gbps are transmitted simultaneously over $50 \mathrm{~km}$ single mode fiber (SMF), plus $15 \mathrm{~m}$ wireless link, 50 $\mathrm{m}$ FSO link, $10 \mathrm{~m}$ wireless respectively. Four selective self-injection locked modes of Qdash laser are utilized as optical carriers for downstream (DS) and upstream (US) transmission. To ensure the matter of mitigation of RB noise, which mainly arises due to the transmission of light-wave of same wavelengths in bidirectional transportation, the carrier signals of different wavelength are used for modulation and remodulation in OLT and ONU. Besides being a strong support to increase the tolerance level against RB noise, this architecture is capable to transmit less noisy information wirelessly in RF sensitive areas too. The constancy of the proposed architecture is evaluated by very low power penalty, clear constellation, prominent eye opening, low bit-error-rate and low error vector magnitude. Therefore, the proposed architecture could be promising alternative not only due to the scheme for mitigation of RB noise but also be a potent in the field of applications of the communication world to provide less noisy information to the multi-users (wired/wireless/FSO).
\end{abstract}

Keywords: Rayleigh backscattering, self-injection locked Qdash laser, WDM-OFDM network.

\title{
Introduction:
}

To fulfill the exponentially increasing demand of pressing bandwidth requirements of the users, development of passive optical network (PON) technology is a promising solution (Y. T. Hsueh et al. 2013). Time-division-multiplexing (TDM) and wavelength division multiplexing (WDM) technologies upgrade the PON systems for broadband services (C. H. Yeh et al. 2008, F. Y. Shih et al. 2010). Several ideas and approaches are reported exploiting TDM-PON systems but still the data rate is inadequate for high resolution video, next generation communication systems (5G), IP networks and multi-services (C. H. Yeh et al. 2012, C.W. Chow et al. 2013, Z. Dong et al. 2015). WDM, time and wavelength division multiplexing (TWDM) technologies perform even better to gratify the thirst of capacity requirements of PON systems for end users (F. Y. Shih et al. 2010, M. Zhu et al. 2013, L. Yi et al. 2013, K. Taguchi et al. 2018). Besides being the backbone of a SMF based optical transport system (G. C. Mandal et al. 2017), a hybrid WDM transport system plays the same role for RF, optical, and wireless based networks too due to its high speed-data rate, wide bandwidth, large coverage range (Chung Yi Li et al. 2016). Furthermore, with the advantages such as high spectral efficiency, strengthen security, good quantifiability, long reach; orthogonal frequency division multiplexing quadrature amplitude modulation (OFDM-QAM) technique pulls the PON systems one step up in advancing to support the broadband services (J. Yu et al. 2008). J. Yu et al. (2008) proposed and demonstrated a WDM-PON system employing QAM modulation for 10 Gbps transmission. In the communication world, free space optics (FSO) communication takes the distinct attenuation to transmit data with high speed and wide bandwidth especially in rural and urban areas without any complications of installation (M. A. Khalighi et al. 2014, A. C. Motlagh et al. 2010). Use of proper and effectual (low power consuming, high efficient, cost effective) light sources in optical line terminal (OLT) and optical network unit (ONU) is also an alternative solution to make the 
transport system more upgraded and advantageous. J. Kani (2010) showed colorless PONs can make the system more efficient and cost effective too. In this scenario, use of Fabry-Perot (FP) laser with injection locking technique instead of employing distributed feedback (DFB) lasers or reflective semiconductor optical amplifiers (RSOA) or its equivalent, which are little bit costly, can be the best solution for cost effectiveness of the system (Z. Xu et al. 2007). In those systems, either a passive device (like, band pass filter) for self-seeding or external seeding sources are used to control FP mode or wavelength of subcarrier. There are several number of works already reported employing light sources with various types of external injection locking schemes for next generation WDM-PON systems with high data capacity (K. Y. Cho et al. 2012, Q.T. Nguyen et al. 2010, M. Cheng et al. 2014, X. Cheng et al. 2006) but power limitation, intensity noise, narrow bandwidth tunability make issues for some of these systems. Later, J. N. Kemal et al. (2017) showed Q-dash laser source with mode locking scheme in WDM system can be able to overcome the limitations mentioned earlier. Furthermore, to make the transport system more acceptable to the upcoming communication system, reuse of wavelength in WDM-PON by employing RSOA can be considered as an alternative solution (I. Cano et al. 2010, P. Parolari et al. 2014). However, bidirectional transmission system performance degrades by unavoidable Fresnel back-reflections and RB noise which arises due to the propagation of signals of same wavelength in both directions and these cause to become worse in case of long-reach WDM-PON (Q. Feng et al. 2015). Several research groups have been proposed and investigated different techniques and architectures to mitigate RB noise (T. Yoshida et al. 2006, C. W. Chow et al. 2007, J. A. Lazaro et al. 2007). C. H. Yeh et al (2012) proposed a technique to minimise RB noise by exploiting unique fiber access network system. Among various reported approaches, crossed network technique might be considered as an effective solution to mitigate RB noise or crosstalk (A. Chiuchiarelli et al. 2009). P. K. Choudhury (2018) reported the technique for enhancement of noise tolerance for $10 \mathrm{Gbps}$ bidirectional crossed network employing spectrally shaped OFDM signal which can be considered as an effective solution to reduce RB noise.

In this paper, a bidirectional hybrid WDM-OFDM network is proposed and demonstrated to transport $\mathrm{RB}$ noise mitigated information for multi-service communication such as, wired/wireless/FSO transmission by employing a multi-wavelength Qdash laser as a source. For this transportation, five selected modes of the laser source with $50 \mathrm{GHz}$ spacing is used to modulate by different data for multi-service communication for both DS and US transmission. Among five, four optical carriers $\lambda_{1}$, $\lambda_{2}, \lambda_{3}, \lambda_{4}$ are selected for modulation for DS transmission and $\lambda_{2}, \lambda_{3}, \lambda_{4}, \lambda_{5}$ are chosen for US transmission. With the assistance of $2 \times 4$ multiplexer/demultiplexer, we are able to separate the DS and US transmission port for bidirectional transmission that ensures the condition for avoiding RB noise, which arises from the transportation of signals of similar wavelength in a single fiber can be gratified. $10 \mathrm{Gbps} / 100 \mathrm{GHz}$ MMW, $10 \mathrm{Gbps} / 16$ QAM OFDM signal, 10 Gbps DPSK signal and 10 Gbps/32 QAM OFDM signals are transmitted successfully over $50 \mathrm{~km}$ SMF as well as $15 \mathrm{~m}$ 
wirelessly, 50m FSO link along with $50 \mathrm{~km} \mathrm{SMF,} 50 \mathrm{~km}$ SMF and $50 \mathrm{~km}$ SMF as well as $10 \mathrm{~m}$ wirelessly for DS transmission respectively. The feasibility of this architecture is evaluated or can be achieved by low BER value, proper EVM value, clear constellation and prominent eye opening. As per our knowledge on the basis of literature survey, this is the very first time where, the architecture for transportation of $10 \mathrm{Gbps}$ data in each of four channels with minimum RB noise over $50 \mathrm{~km} \mathrm{SMF}$ for multi-users (wired/wireless/FSO link) is projected and examined.

\section{Quantum dash laser source:}

Now a days, quantum dash laser diodes attracts considerable attention owing to unrivalled potential to deliver a number of advantages such as very high gain, lower threshold current, higher thermal stability over bulk based devices or quantum well devices (N. N. Ledentsov et al. 2000). By providing broad gain spectrum and first carrier dynamics Qdash mode locked laser makes itself more impressive and attractive in the field of application in communication world (F. Lelarge et al. 2007). Several Qdash lasers based on InAs/GaAs, that operating in the $1.3 \mu \mathrm{m}$ window already gathered faith by its marvelous performance through thermal stability, high differential gain etc. InAs/InP based Qdash lasers are more appreciable to the telecommunication world for its operating window range (1.4-1.6 $\mu \mathrm{m})($ N. N. Ledentsov et al. 2000, D. Bimberg et al. 1997, M. Sugawara et al. 2000, J. P. Reithmaier et al. 2002). A self-injection locked laser diode is employed as multi-wavelength source with flat and wide optical spectrum centered at $1555 \mathrm{~nm}$ that ensues the reduction of the number of sources too for providing multiservice to the users. To maintain the continuity of the experiment in OLT/ONU section from source, compatibility condition between channel spacing of the tunable AWG and mode spacing of Qdash laser must be required or mandatory that means the frequency and the channel spacing of tunable AWG must be adjusted in such way that, it concurs with that of the modes of Qdash laser. In our set up to fulfill the compatibility condition between mode spacing of Qdash laser and $50 \mathrm{GHz}$ channel spacing of tunable AWG, optimization of cavity length of the Qdash laser is exploited. By matching the mode spacing with channel spacing, use of an individual channel frequency controller could be avoided. Each of the channels generated from mode-locked laser source is coherent and besides that, different channels of AWG are specified for different selected modes of the Qdash laser. Gas source molecular beam epitaxy (GSMBE) on S-doped (100) InP wafer is employed to grow up the Qdash based heterostructure using "self-organized" Stransky-Krastanow growth mode (F. Lelarge et al. 2007, R. Rosales 2012). The active layer structure of dashes-in-barrier design consisting of 6 layers of InAs Qdashes (emitting at $1.55 \mu \mathrm{m}$ ), that is separated by InGaAsP barriers $\left(\lambda_{\mathrm{g}}=1.23 \mu \mathrm{m}\right)$ is employed here. The typical diameter and height of Qdash are $19 \mathrm{~nm}$ and 2.4 $\mathrm{nm}$ respectively with density of Qdash per layer is $2.5 \times 10^{10} \mathrm{~cm}^{-2}$. The operating current of Qdash mode locked laser diode is $310 \mathrm{~mA}$. The made-up lasers are sliced at a length of $840 \mu \mathrm{m}$ to get adequate channel spacing. Moreover, increase of relative intensity noise (RIN) of selected mode especially in low frequency makes an obstacle when, amplified Qdash lasers are used as a WDM 
source. Self-injection locking technique could be considered as an incredible solution to reduce RIN effect by going through new lasing regime with higher resonance frequency (G. C. Mandal et al. 2018). For generation of self-injection locked five comb optical carriers from the Qdash laser diode, an optical circulator (OC), an erbium-doped fiber amplifier (EDFA) of gain $+20 \mathrm{~dB}$, a coupler (CP) of $3 \mathrm{~dB}$, TBPF are employed in the OLT section depicted in fig 1 . A $50 \%$ of the total laser power passed through OC and EDFA is fed back into the laser via CP. The TBPF, which is employed in the feedback path, controls the multiple selective modes for re-injection into the laser active region through OC for self-injection locking purpose (M. A. Shemis, et al. 2017). A 1x4 AWG is utilized after $\mathrm{CP}$ to achieve larger side mode suppression ratio (SMSR $>55 \mathrm{~dB}$ ) of selected $50 \mathrm{GHz}$ spacing optical carriers.

\section{Experimental setup:}

The block diagram of our proposed experimental set up for transportation of Rayleigh backscattering noise eliminated information for multiservice communication based on a self-injection locked Qdash laser source is depicted in fig 1. The principle of this architecture is unfolded by three main sections of the set up namely optical line unit (OLT), remote node (RN) and optical network unit (ONU). In OLT, self-injection locked quantum dash laser diode (QD-LD) is used as a multi wavelength laser source. At the output of the QD-LD, four different wavelengths $\lambda_{1}, \lambda_{2}, \lambda_{3}, \lambda_{4}\left(\lambda_{1}=1554.2 \mathrm{~nm}\right.$, $\lambda_{2}=1554.6 \mathrm{~nm}, \lambda_{3}=1555 \mathrm{~nm}, \lambda_{4}=1555.4 \mathrm{~nm}$ ) are selected to regard as optical carriers and transmit

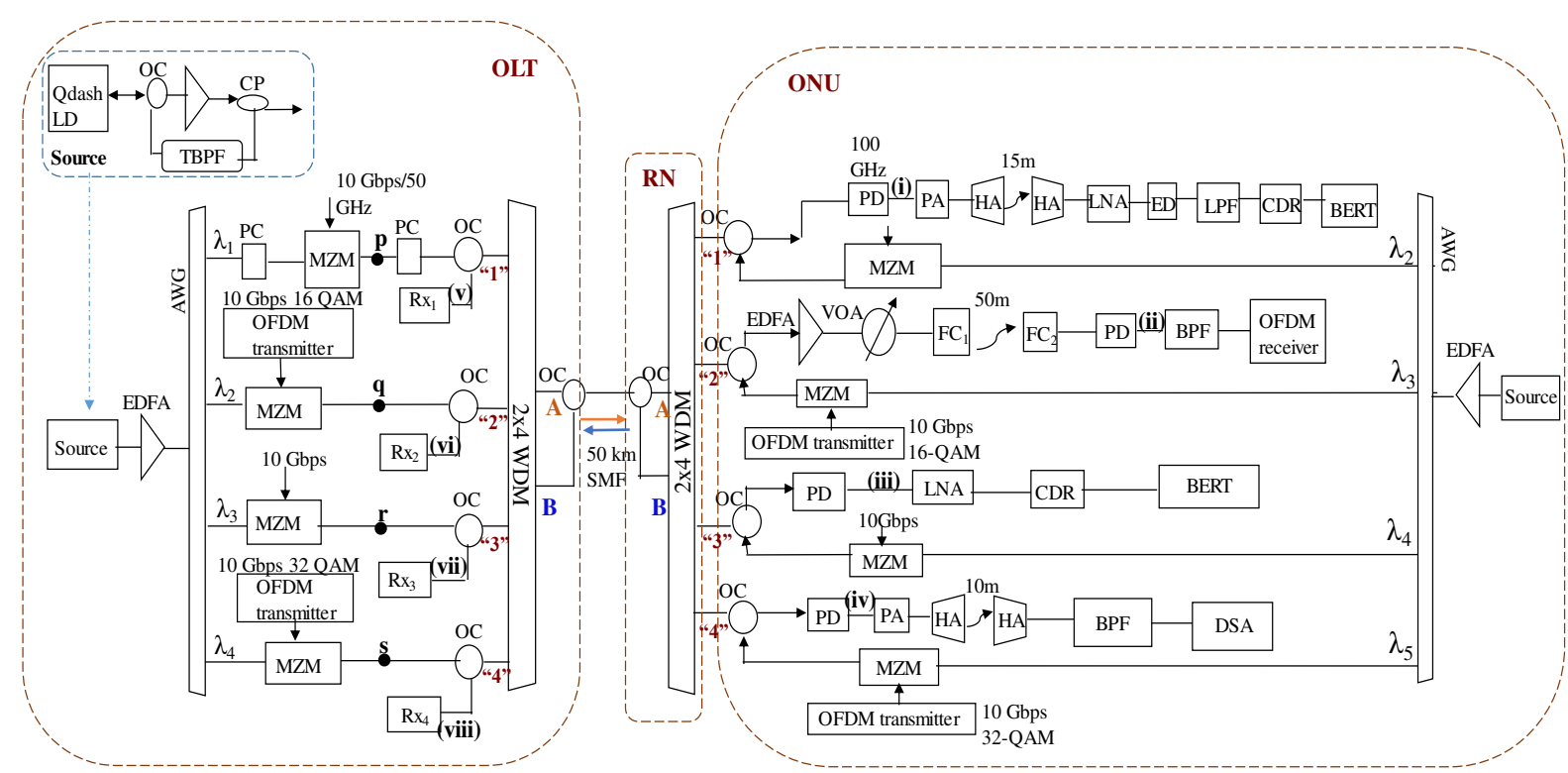

Fig. 1. block diagram of proposed bidirectional hybrid WDM-OFDM network for transportation of Rayleigh Backscattering noise eliminated information for multiservice communication by employing a self-injection locked Qdash laser source.

through AWG for DS transmission. The $\lambda_{1}$ carrier signal of central wavelength $1554.2 \mathrm{~nm}$ fed into Mach-Zehnder modulator (MZM) through polarization controller (PC) and modulated by $10 \mathrm{~Gb} / 50 \mathrm{GHz}$ signal. By properly biasing the MZM, signal of carrier suppressed double side bands with angular frequencies $\left(\omega_{\mathrm{c}}+\omega_{\mathrm{RF}}\right)$ and $\left(\omega_{\mathrm{c}}-\omega_{\mathrm{RF}}\right)$ can be produced where, $\omega_{\mathrm{c}}$ and $\omega_{\mathrm{RF}}$ present the 
angular frequency of carrier and modulating RF signal respectively. When MZM is driven by laser source at half wave voltage $\left(\mathrm{V}_{\pi}=4.8 \mathrm{v}\right)$, phase shift between two arms produced in such a way that ensued a suppressed carrier modulation format (R. Montgomery et al. 1995). A 10 Gbps pseudo random bit sequence (PRBS) on-off keying data stream with $2^{31}-1$ word length is mixed with the 50 $\mathrm{GHz}$ RF signal in modulator. The output of the modulator can be expressed with amplitude 'A', which consisting of modulation index and amplitude of signals as

$$
A\left[\cos \left(\omega_{c}-\omega_{R F}\right) t+\cos \left(\omega_{c}+\omega_{R F}\right) t\right.
$$

A PC is used to control the state of polarization of the modulated signal and it is fed into $2 \times 4$ WDM multiplexer via OC. Another wavelength $\lambda_{2}(=1554.6 \mathrm{~nm})$ from multi-wavelength laser source is modulated by $10 \mathrm{Gbps} / 16$ QAM OFDM data in another MZM. The OFDM transmitter consists of serial to parallel (S/P) converter, QAM modulation, inverse fast Fourier transform (IFFT) followed by cyclic prefix (CP) and digital to analog converter (DAC). From an arbitrary waveform generator (AWG), a OFDM data with 16-QAM modulation format, 8-bit resolution, 10GS/s, 1/32 CP, 512-point FFT is generated by using MATLAB programming and then it serves as DS data stream and is sent to $2 \times 4$ WDM multiplexer through an OC. Carrier signal with center wavelength at $\lambda_{3}(=1555 \mathrm{~nm})$ modulated by a $\mathrm{LiNbO}_{3}$ MZM with $10 \mathrm{Gbps}$ differential phase shift keying (DPSK) format and used as DS signal. From an another OFDM transmitter $10 \mathrm{Gbps}$ OFDM data with same specifications as earlier except different QAM modulation format i.e. 32-QAM modulation which is mixed with 100 $\mathrm{MHz}$ radio frequency (RF) signal is used to modulate the carrier wavelength $\lambda_{4}(=1555.4 \mathrm{~nm})$ employing MZM for one more DS data stream. Finally, all four modulated carriers serve as DS data are multiplexed by $2 \times 4$ WDM multiplexer then launched to RN section and transmitted over $50 \mathrm{~km}$ SMF. A 2x4 WDM multiplexer/demultiplexer de-multiplexed the DS data for detection. The output characteristic of $2 \times 4$ WDM multiplexer mainly takes part in the foremost role to make this transport system more defensible to the next generation communication system by transmitting less noisy information for users for multiservice. Here, two ports of WDM multiplexer are utilized for DS and US transmission. In this architecture, $\lambda_{1}$ to $\lambda_{4}$ wavelengths are only granted to pass through port " $\mathrm{A}$ " while $\lambda_{2}$ to $\lambda_{5}$ are permitted through port "B" from input/output port of WDM multiplexer. In our set up, at output/input port " 1 " of the multiplexer, $\lambda_{1}$ serves as DS and $\lambda_{2}$ used for US transmission and similarly, for port "2" to "4", $\lambda_{2}$ and $\lambda_{3}, \lambda_{3}$ and $\lambda_{4}, \lambda_{4}$ and $\lambda_{5}$ are used for DS and US transmission respectively. So it can be asserted that, this architecture can successfully able to minimize the RB noise which arises when the signals having similar wavelengths transmit through a single fiber.

Lastly, at ONU, detection of DS signals and remodulation of data for US transmission transpires. For US transmission, an another tunable Qdash laser diode is used as a source and by properly tuning the band pass filter (BPF), particular Fabry-Perot (FP) modes are selected for using it as optical carrier at ONU. Four different wavelengths $\lambda_{2}, \lambda_{3}, \lambda_{4}, \lambda_{5}\left(\lambda_{2}=1554.6 \mathrm{~nm}, \lambda_{3}=1555 \mathrm{~nm}, \lambda_{4}=1555.4 \mathrm{~nm}, \lambda_{5}=1555.8\right.$ 
$\mathrm{nm}$ ) are selected as optical carriers and transmit through AWG. From the very first port of WDM multiplexer (i.e. port "1") transmitted $10 \mathrm{Gbps} / 100 \mathrm{GHz} \mathrm{MMW}$ signal is detected with the assistance of a $100 \mathrm{GHz} \mathrm{PD}$ and then a power amplifier (PA) amplified the signal and fed it into a $100 \mathrm{GHz}$ horn antenna (HA) for wireless transmission of $15 \mathrm{~m}$. A $100 \mathrm{GHz}$ PD (3dB bandwidth) with responsivity $0.5 \mathrm{~mA} / \mathrm{mW}$ at $1550 \mathrm{~nm}$ with detection wavelength range of $1480-1620 \mathrm{~nm}$ is used here. Another 100 $\mathrm{GHz}$ HA received this $10 \mathrm{Gbps} / 100 \mathrm{GHz}$ signal then it delivered to an envelope detector (ED) for down conversion and the signal is boosted by using a $100 \mathrm{GHz}$ low noise amplifier (LNA). A $10 \mathrm{GHz}$ low pass filter (LPF) and a clock data recovery (CDR) are used to filter out and to recover clock/data respectively and finally the signal performance is examined by feeding it into a bit error rate taster (BERT). A selected wavelength of carrier signal $\lambda_{2}(=1554.6 \mathrm{~nm})$ from Qdash LD is remodulated by 10 Gbps signal at MZM then reached to port "1" of WDM multiplexer through a circulator OC for US transmission. From port "2" a 10 Gbps OFDM signal/data launched into an amplifier through OC for free space communication purpose. By employing amplifier and variable optical attenuator (VOA) the DS signal is amplified and attenuated respectively. Further it is communicated over a free space link through two identical free space optical (FSO) terminals (i.e. fiber-based collimator $\mathrm{FC}_{1}$ and $\mathrm{FC}_{2}$ ). With the aid of fine tracking technology of $\mathrm{FC}_{1}$ and $\mathrm{FC}_{2}$, signal is communicated over $50 \mathrm{~m}$ in free space. A $10 \mathrm{GHz}$ PD detects the signal and further it is fed into a band pass filter (BPF) to elude the noise that arises due to free space communication purpose. Finally, this signal is received by an OFDM receiver. In OFDM receiver, QAM demodulation format, Fast Fourier transform (FFT), equalizer, serial-to-parallel (S/P), guard removal and analog to digital converter (ADC), all are performed together for receiving data and digital signal processing (DSP) technique is used to recover the OFDM data. The carrier wavelength $\lambda_{3}(=1555 \mathrm{~nm})$ is remodulated by $10 \mathrm{Gbps} / 16-\mathrm{QAM}$ OFDM signal in MZM and through OC, it reached to port "2" for US transmission. Another 10Gbps DS data reached to a PD through OC from port "3" of WDM multiplexer. Here, $10 \mathrm{GHz}$ PD plays the role of a baseband (BB) signal detector that detects the BB signal and further amplified by a booster amplifier LNA. To recover and regenerate the data of BB signal a $10 \mathrm{GHz}$ CDR is employed. Finally, BERT evaluates the signal performance. Simultaneously, an optical carrier of wavelength $\lambda_{4}(=1555.4 \mathrm{~nm})$ from source is remodulated by 10 Gbps DPSK signal at MZM and reaches to port " 3 " for US transmission through OC. A $10 \mathrm{GHz}$ PD is used to detect $10 \mathrm{Gbps} / 32$-QAM OFDM signal that reaches at ONU through port "4" of this multiplexer. Further, signal is boosted by $10 \mathrm{GHz}$ PA and communicated wirelessly over $10 \mathrm{~m}$ distance with collaboration of two HAs (frequency range 100 MHz-1 GHz, maximum continuous power $=800$ watt, VSWR < 1.6:1). A $10 \mathrm{GHz}$ BPF filter out the signal and recovered by offline digital signal processing (DSP) in a real time scope (DSA). A carrier signal $\lambda_{5}(=1555.8 \mathrm{~nm})$ is remodulated by $10 \mathrm{Gbps} / 32$-QAM signal with the aid of MZM for US link. All these US data transmit through port "B" of WDM multiplexer from ONU to OLT and received by same way as they are detected at ONU. 


\section{Results and discussions:}

The optical spectra of self-injection locked modes of Qdash laser with free running spectrum is presented in fig 2 and it is also clear that, five equally spaced spectra reveal high SMSR value (>55 $d B)$. Fig 3(a) and 3(b) show the carrier signals used for DS and US transmission at a glance $\left(\lambda_{1}, \lambda_{2}, \lambda_{3}\right.$, $\lambda_{4}$ for DS and $\lambda_{2}, \lambda_{3}, \lambda_{4}, \lambda_{5}$ for US). Optical spectra of different optical signals are depicted in fig 4(a)(e) [insert in fig 1]. Fig 4(a) shows the optical spectrum of $10 \mathrm{Gbps} / 100 \mathrm{GHz}$ modulated signal with carrier frequency and fig 4(b) presents the spectrum for same signal at the output of the modulator at 'p' insert in fig 1. Similarly, fig 4(c), 4(d) and 4(e) represent the optical spectra of modulated signals at the output of modulators at point 'q', 'r' and 's' respectively insert in fig 1. Electrical spectra of DS and US signals after detected by detectors at the receiving section of ONU and OLT are depicted in fig 5(i)-(viii).

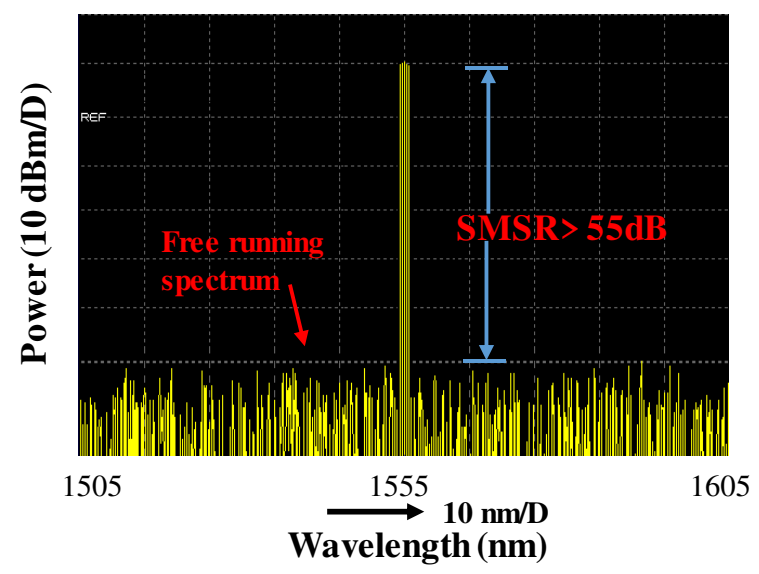

Fig.2. five self-injection locked modes of Qdash laser.
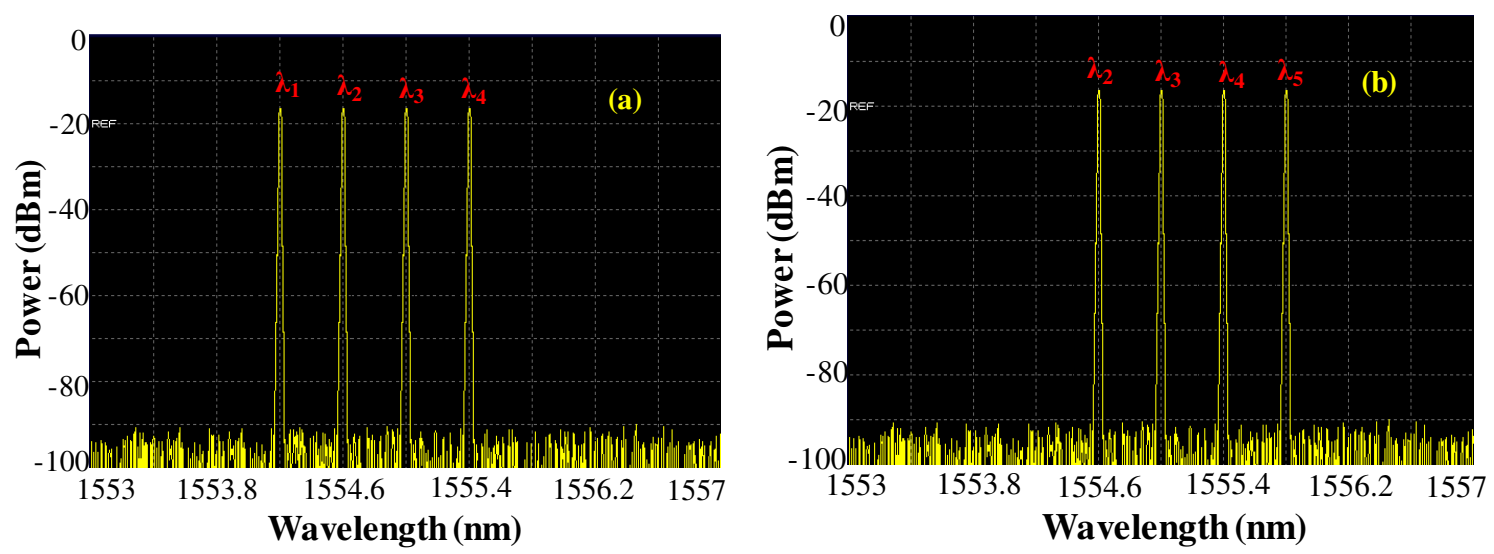

Fig.3(a). carrier signals for modulation of data for DS transmission Fig.3(b). carrier signals for modulation of data for US transmission 

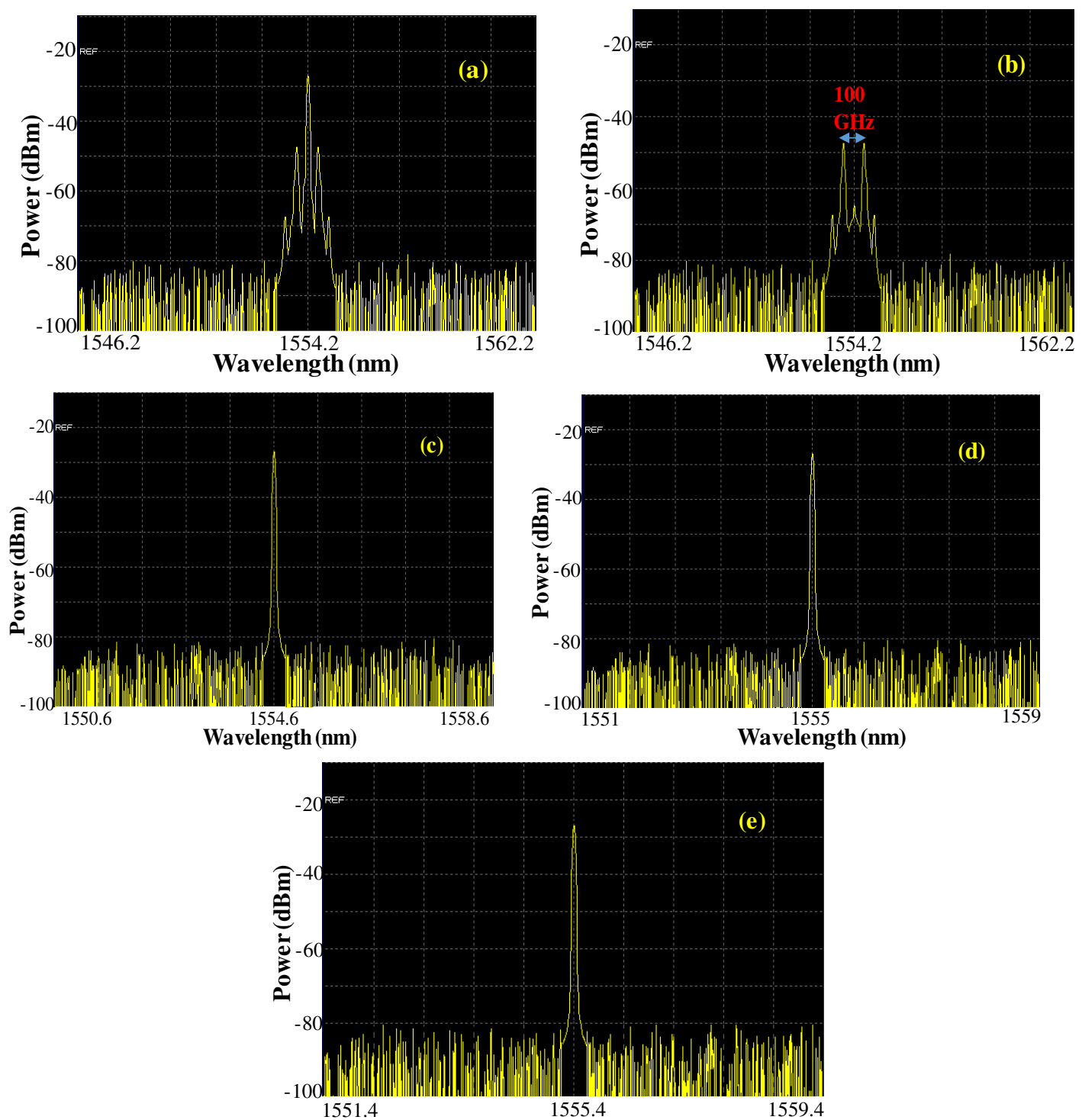

Fig.4 optical spectrum of (a) $10 \mathrm{Gbps} / 100 \mathrm{GHz}$ modulated signal with carrier frequency and (b)-(e) at the output of the modulators for respective channels (insert 'p'- 's' of fig.1)
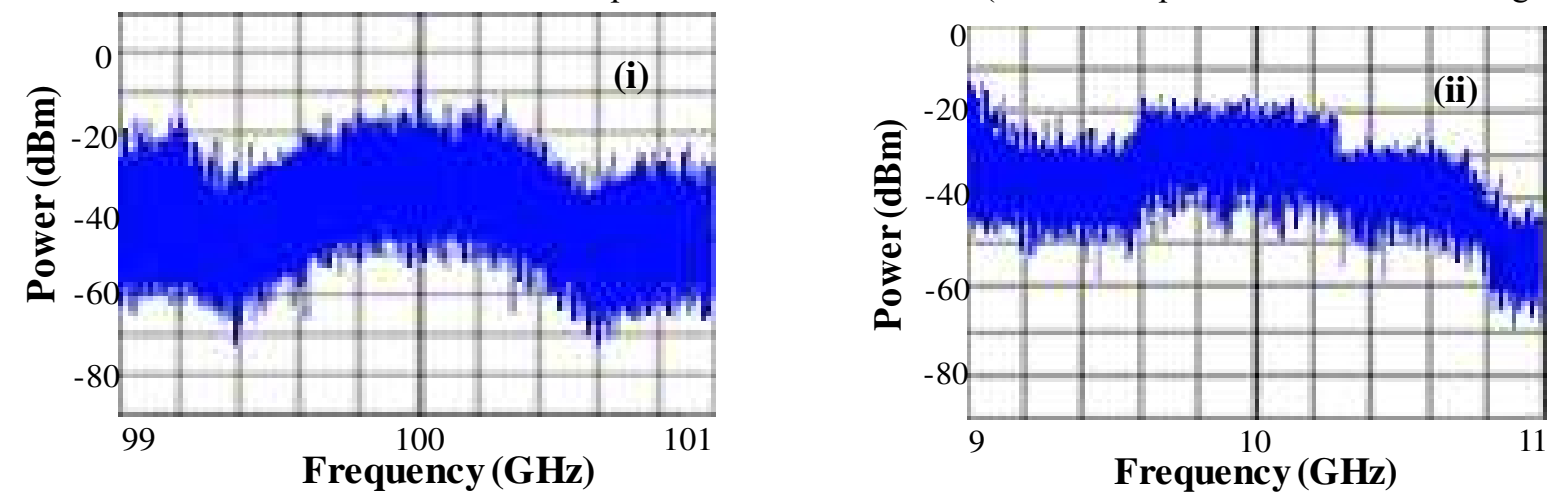

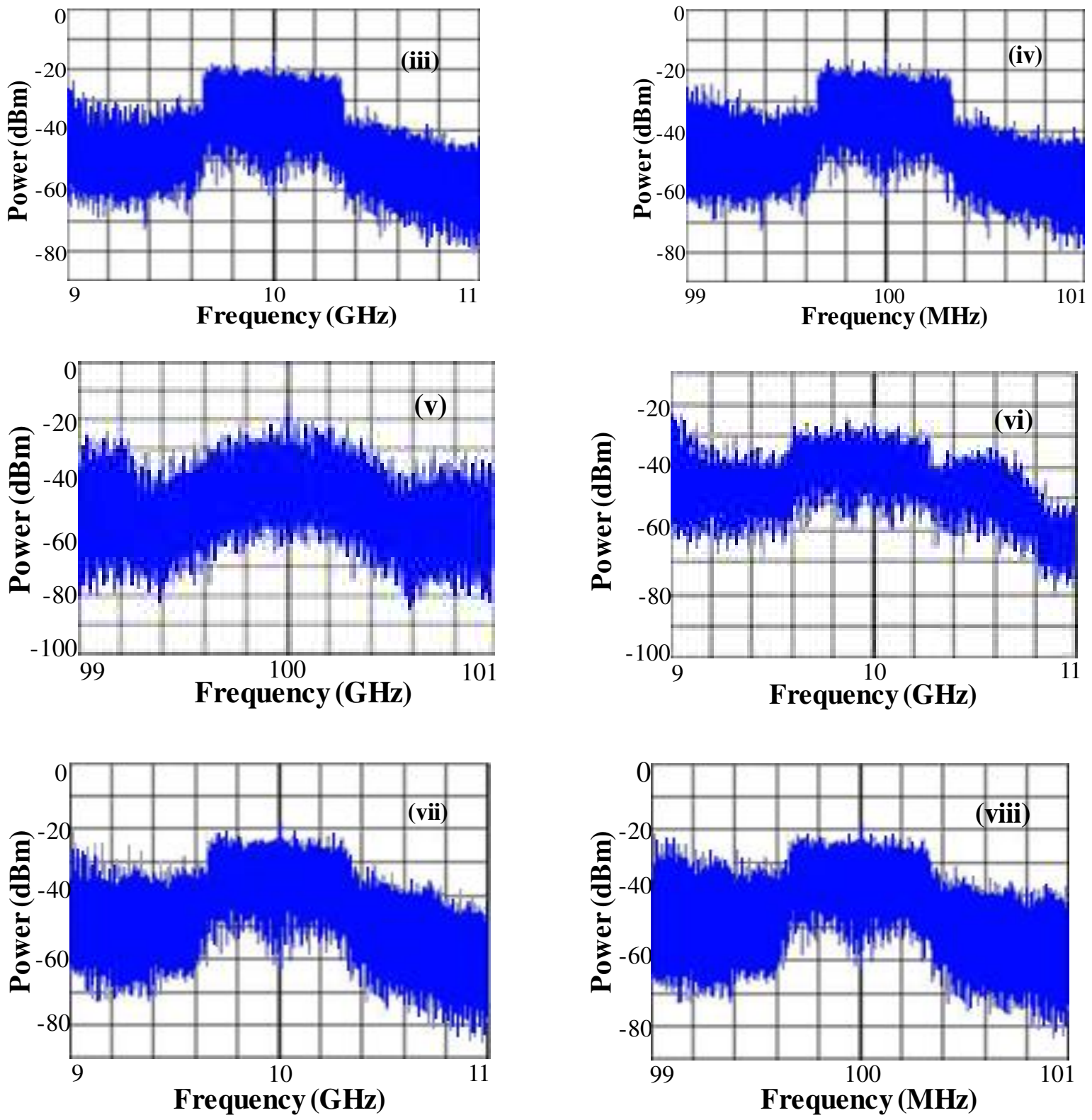

Fig.5 (i)-(viii) Electrical spectra at some important points of electrical path [insert (i)-(viii) of fig.1]

Fig.6 shows measured $\log (\mathrm{BER})$ vs received optical power graph along with eye diagrams for 10 Gbps/100 GHz MMW signal for both B2B and over $50 \mathrm{~km} \mathrm{SMF}$ as well as $15 \mathrm{~m}$ wireless DS transmission. This signal achieved $-13.55 \mathrm{dBm}$ receiver sensitivity at BER value of $6.24 \times 10^{-9}$. Very low power penalty around $1.5 \mathrm{dBm}$ is recorded between B2B and $50 \mathrm{~km}$ SMF along with $15 \mathrm{~m}$ wireless transmission distance. Employment of LNA and CDR schemes ensue the improvement of BER performance and eye diagrams as this scheme suppresses the fluctuations of the phase and amplitude and amplifies the signal simultaneously (K. Mallick et al. 2019). Measured $\log (\mathrm{BER})$ value vs received optical power curve and constellation diagrams for 10 Gbps 16-QAM OFDM signal are depicted in fig 7. Receiver sensitivity of $-18.6 \mathrm{dBm}$ at BER $3.6 \times 10^{-3}$ (under FEC limit) is achieved by 10 Gbps 16-QAM OFDM data for $50 \mathrm{~km}$ SMF plus $50 \mathrm{~m}$ FSO link. A $2.4 \mathrm{dBm}$ power penalty is 


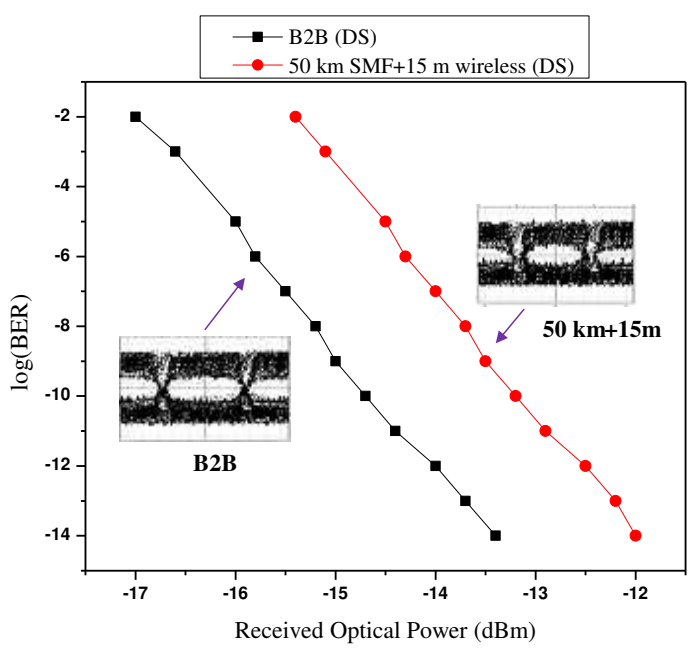

Fig.6. $\log (\mathrm{BER})$ values as a function of receiver optical power and eye diagram for $10 \mathrm{Gbps} / 100$ GHz MMW signal.

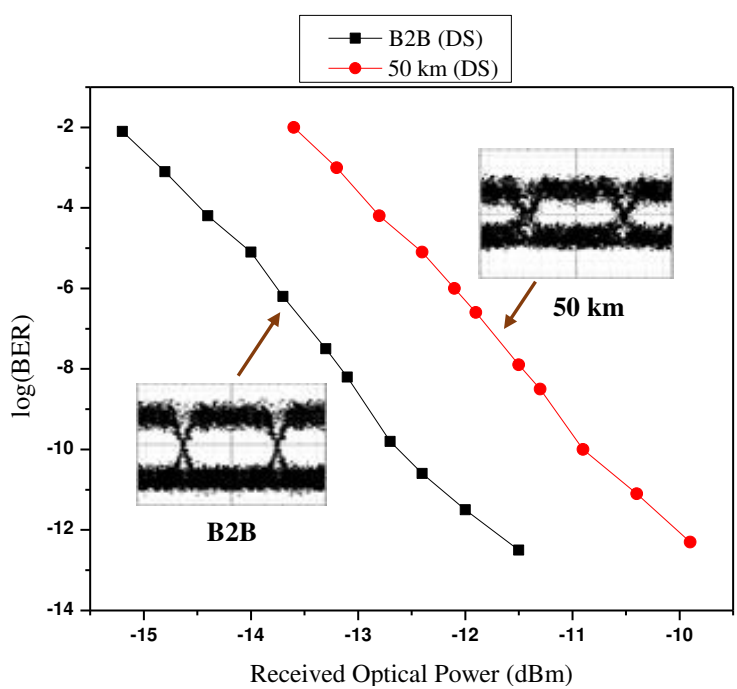

Fig. 8. $\log (\mathrm{BER})$ values as a function of receiver optical power and eye diagram for $10 \mathrm{Gbps} \mathrm{BB}$ signal.

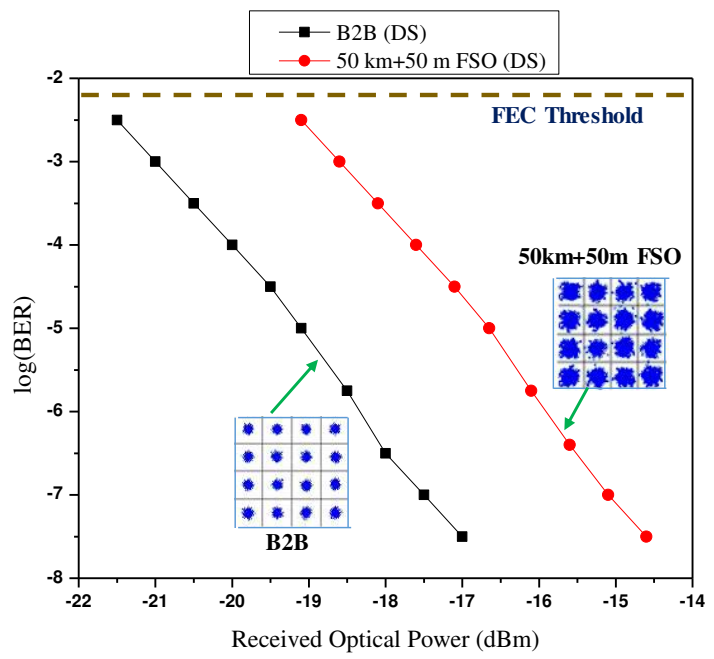

Fig.7. $\log (\mathrm{BER})$ values as a function of receiver optical power and constellation diagrams for 10 Gbps 16 QAM OFDM signal.

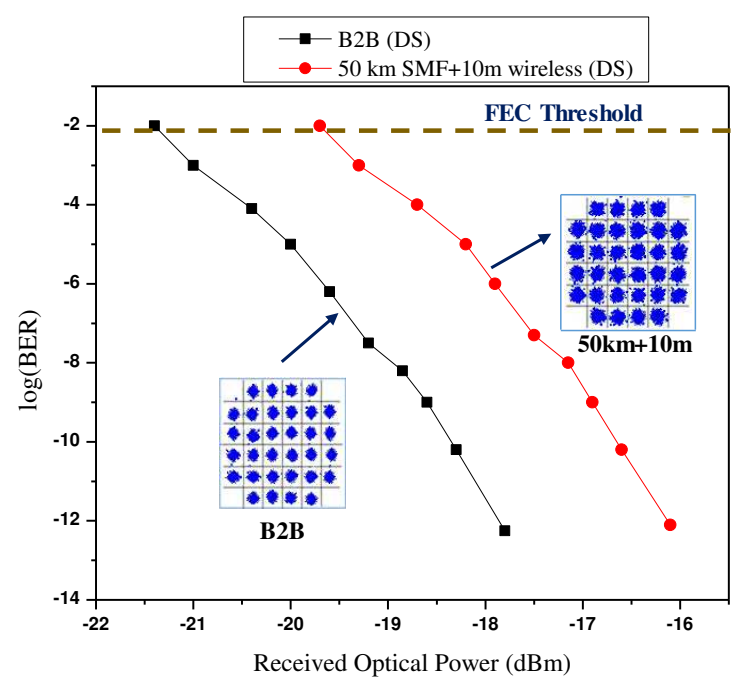

Fig.9. $\log (\mathrm{BER})$ values as a function of receiver optical power and constellation diagrams for 10 Gbps 32 QAM OFDM signal.

recorded between B2B and $50 \mathrm{~km} \mathrm{SMF}$ along with $50 \mathrm{~m}$ FSO for DS transmission. For 16-QAM signal transmission, $12.15 \%$ and $12.3 \% \mathrm{EVM}$ values are observed for $\mathrm{B} 2 \mathrm{~B}$ and $50 \mathrm{~km} \mathrm{SMF}+50 \mathrm{~m}$ FSO link respectively from constellation diagrams of fig 7. Fig 8 gives the $\log (\mathrm{BER})$ vs received optical power graph and eye diagrams for $10 \mathrm{Gbps} \mathrm{BB}$ signal for both B2B and over $50 \mathrm{~km} \mathrm{SMF}$. A $1.4 \mathrm{dBm}$ power penalty between B2B and over $50 \mathrm{~km}$ SMF transmission and receiver sensitivity of $11.2 \mathrm{dBm}$ is achieved at $8.1 \times 10^{-9}$ BER. Relationship between $\log (\mathrm{BER})$ and received optical power for $10 \mathrm{Gbps} 32-\mathrm{QAM}$ OFDM signal and constellation diagrams for both B2B and over $50 \mathrm{~km} \mathrm{SMF}$ as well as $10 \mathrm{~m}$ wireless link for DS transmission are presented in fig 9 . The receiver sensitivity of -19.3 $\mathrm{dBm}$ with BER $3.75 \times 10^{-3}$ (under FEC limit) for $10 \mathrm{Gbps} 32$-QAM data signal after passing over 50 $\mathrm{km}$ SMF plus $10 \mathrm{~m}$ wireless link. Very low power penalty of $1.7 \mathrm{~dB}$ is observed between B2B and 50 $\mathrm{km}$ SMF+10m wireless link for DS transmission at BER of $10^{-3}$. Clear constellation diagrams with 
EVM values of $9.5 \%$ and $9.7 \%$ are observed respectively for B2B and over $50 \mathrm{~km}+10 \mathrm{~m}$ wireless link for 32-QAM signal transmission from fig 9.

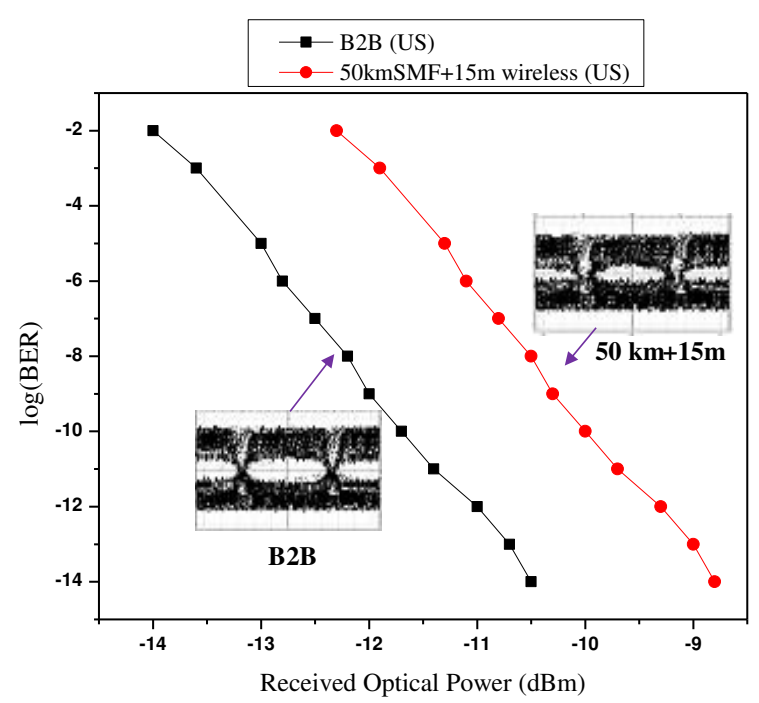

Fig.10. $\log (\mathrm{BER})$ values as a function of receiver optical power and eye diagram for $10 \mathrm{Gbps} / 100$ GHz MMW signal.

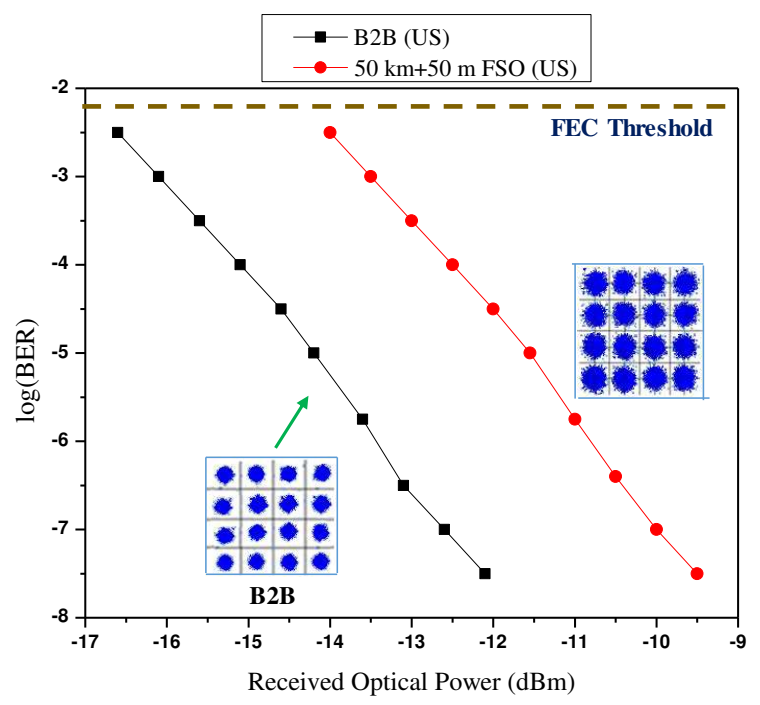

Fig.11. $\log (\mathrm{BER})$ values as a function of receiver optical power and constellation diagrams for 10 Gbps 16 QAM OFDM signal.

Variation of measured BER value as a function of received optical power along with eye diagrams for $10 \mathrm{Gbps} / 100 \mathrm{GHz}$ MMW signal for US transmission are presented in fig 10. Receiver sensitivity of $10.3 \mathrm{dBm}$ is achieved by the signal at BER $6.12 \times 10^{-9}$. A successful transmission of $10 \mathrm{Gbps} / 100 \mathrm{GHz}$ MMW signal over $50 \mathrm{~km} \mathrm{SMF}$ along with $15 \mathrm{~m}$ wireless link is indicated by low power penalty of 1.7 $\mathrm{dB}$ and prominent eye opening as seen in fig 10. Fig. 11 shows the measured BER curve with received optical power for 10 Gbps 16-QAM OFDM signal along with constellation diagrams for $\mathrm{B} 2 \mathrm{~B}$ and $50 \mathrm{~km} \mathrm{SMF+50} \mathrm{m} \mathrm{FSO} \mathrm{transmission} \mathrm{of} \mathrm{US} \mathrm{link.} \mathrm{Receiver} \mathrm{sensitivity} \mathrm{of}-13.5 \mathrm{dBm}$ with $3.65 \times 10^{-3}$ BER value is achieved by the signal. Power penalty of $2.6 \mathrm{~dB}$ is recorded between $\mathrm{B} 2 \mathrm{~B}$ and $50 \mathrm{~km}$ SMF as well as $50 \mathrm{~m}$ FSO link transmission. Clear constellations with $12.27 \%$ and $12.35 \%$ $\mathrm{EVM}$ value for $\mathrm{B} 2 \mathrm{~B}$ and $50 \mathrm{~km} \mathrm{SMF}+50 \mathrm{~m}$ FSO transmission is observed. Variation of $\log (\mathrm{BER})$ values with received optical power and eye diagrams for $10 \mathrm{Gbps}$ BB signal for B2B and over $50 \mathrm{~km}$ SMF for US transmission is depicted in fig 12 . Receiver sensitivity of $-7.75 \mathrm{dBm}$ with $7.12 \times 10^{-9} \mathrm{BER}$ value is achieved. Power penalty of $1.6 \mathrm{~dB}$ which is considerably low for US transmission is recorded between B2B and over $50 \mathrm{~km}$ SMF. Clear eye opening is observed for both cases and is presented in fig 12. Fig 13 shows the measured $\log (\mathrm{BER})$ curve as a function of received optical power for 10 Gbps 32 QAM OFDM signal transmission over $50 \mathrm{~km}$ SMF along with $10 \mathrm{~m}$ wireless link for US link. Receiver sensitivity of $-15.5 \mathrm{dBm}$ is achieved at BER of $3.8 \times 10^{-3}$ (under FEC limit) by the signal for $50 \mathrm{~km} \mathrm{SMF}+10 \mathrm{~m}$ wireless link. Power penalty of $1.8 \mathrm{~dB}$ is observed between $\mathrm{B} 2 \mathrm{~B}$ and $50 \mathrm{~km}$ SMF as well as $10 \mathrm{~m}$ wireless transmission at BER of $10^{-3}$. Clear constellations for US transmission of $10 \mathrm{Gbps} 32-\mathrm{QAM}$ OFDM signal for B2B and $50 \mathrm{~km}+10 \mathrm{~m}$ wireless link with appreciable EVM values (9.65\% and $9.85 \%$ for both cases respectively as mentioned earlier) are observed in fig 13. 


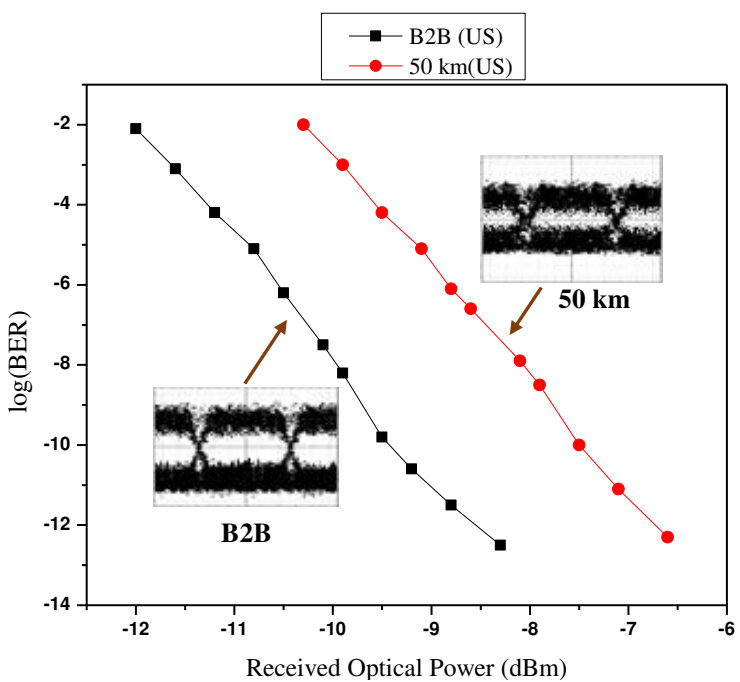

Fig.12. $\log (\mathrm{BER})$ values as a function of receiver optical power and eye diagram for $10 \mathrm{Gbps} \mathrm{BB}$ signal.

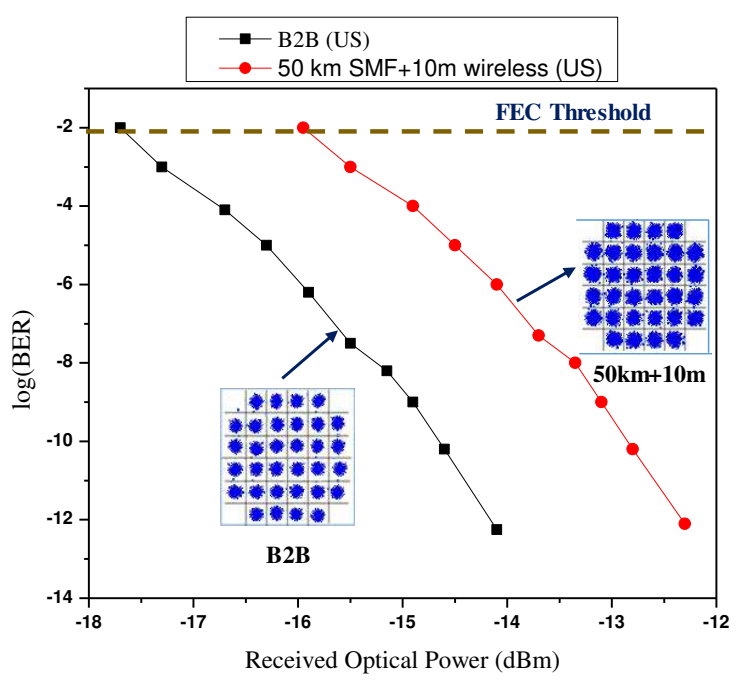

Fig.13. $\log (\mathrm{BER})$ values as a function of receiver optical power and constellation diagrams for 10 Gbps 32QAM OFDM signal.

In bidirectional transmission system, when two signals of similar wavelength transmit through a single fiber for DS and US transmission, amount of loss due to Rayleigh backscattering specially for pure silica glass can be expressed approximately by, $A_{1}(\lambda)=A_{0}\left(\frac{\lambda_{*}}{\lambda}\right)^{4}$ with $\mathrm{A}_{0}=0.148 \mathrm{~dB} / \mathrm{km}$ at $\lambda$ * $=1550 \mathrm{~nm}$ (J. W. Simatupang et al. 2016). The experimental values can be compared with theoretical values by using theoretical expression which proves the reliability of the proposed set up. For comparison purpose, a power meter could be connected temporarily to the OCs at OLT for each channel to measure the scattering loss arises from $50 \mathrm{~km} \mathrm{SMF}$ along with wireless transmission path for respective channels for DS transmission. The values of scattering loss that measured from experiment and the exact values from theoretical expression are listed in Table 1.

Table 1: The Comparison of loss due to Rayleigh backscattering effect

\begin{tabular}{|c|c|l|c|}
\hline $\begin{array}{c}\text { When same carrier signals are used for both DS } \\
\text { and US transmission }(\mathrm{nm})\end{array}$ & \multicolumn{2}{c|}{$\begin{array}{c}\text { When different carrier signals are used for DS } \\
\text { and US transmission (nm) }\end{array}$} \\
\hline Theoretical value & Loss in dB & Measured value & Loss in dB \\
\hline 1554.2 & 7.320 & $\begin{array}{l}\text { For DS transmission 1554.2 } \\
\text { For US transmission 1554.6 }\end{array}$ & $1.5-1.7$ \\
\hline 1554.6 & 7.312 & $\begin{array}{l}\text { For DS transmission 1554.6 } \\
\text { For US transmission 1555 }\end{array}$ & $2.4-2.6$ \\
\hline 1555 & 7.305 & $\begin{array}{l}\text { For DS transmission 1555 } \\
\text { For US transmission 1555.4 }\end{array}$ & $1.4-1.6$ \\
\hline 1555.4 & 7.297 & $\begin{array}{l}\text { For DS transmission 1555.4 } \\
\text { For US transmission 1555.8 }\end{array}$ & $1.7-1.8$ \\
\hline & & &
\end{tabular}


From Table 1. it is clear that, the measured value of total loss for transportation of data is significantly lesser than theoretical expectation as this architecture resists the transmission of more than one signals of similar wavelength through a single fiber. Thus it can be negotiated that our proposed architecture proves its potential by reducing RB noise effectively in transportation of information to the multiuser even in bidirectional transmission network.

\section{Conclusion:}

In summary, a novel scheme for bidirectional hybrid WDM-OFDM network for transportation of information to the multi-users (wired/wireless/FSO) with minimum RB noise is proposed and demonstrated. $4 \mathrm{X} 10 \mathrm{Gbps}$ data is transmitted over long distance through 50Km SMF as well as wirelessly with minimum noise by this bidirectional architecture in downlink and uplink. Negligible power penalty is recorded for each channel for DS and US transmission. Good BER value, clear and prominent eye opening prove the fruitful transmission of $10 \mathrm{Gbps} / 100 \mathrm{GHz} \mathrm{MMW}$ signal and $10 \mathrm{Gbps}$ BB signal over $50 \mathrm{~km} \mathrm{SMF+15} \mathrm{m} \mathrm{wireless} \mathrm{and} \mathrm{over} 50 \mathrm{~km}$ SMF respectively. And a successful transmission of 10 Gbps 16 QAM OFDM and 10 Gbps 32 QAM OFDM signal over $50 \mathrm{~km} \mathrm{SMF+50}$ $\mathrm{m}$ FSO and over $50 \mathrm{~km} \mathrm{SMF+10} \mathrm{m} \mathrm{wireless} \mathrm{link} \mathrm{respectively} \mathrm{are} \mathrm{presented} \mathrm{by} \mathrm{good} \mathrm{BER} \mathrm{value,} \mathrm{low}$ power penalty under FEC limit $\left(3.8 \times 10^{-3}\right)$, clear constellations with impressive EVM values $(<12.4 \%$ for 16 QAM, <10\% for 32 QAM). To serve information to the multi-users, employment of selfinjection mode locked Qdash laser as a multi-wavelength source could be a smart step to avoid a number of laser source. This architecture can provide less noisy information to the wired users and wireless users through wireless and FSO link and it also capable to transmit information in RF sensitive areas like hospitals, children schools, healthcare centers. Therefore, we assert, our proposed architecture could be a sterling alternative to the next generation communication (e.g. 5G) world as it can fulfil the thirst (i.e. high data rate transmission with minimum noise) of $5 \mathrm{G}$ by providing information to the multi-users (wired/wireless/FSO) with minimum impairments due to RB noise.

Acknowledgement: Authors would like to thank Sidho-Kanho-Birsha University, Purulia, West Bengal, India for providing the infrastructural support and SERB, CRG/2019/006580, Govt. of India for financial support to carry the research work.

\section{References:}

Hsueh, Y. T., Huang, M. F., Fan, S. H., Chang, G. K.: A novel lightwave centralized bidirectional hybrid access network Seamless integration of RoF with WDM-OFDM-PON. IEEE Photonics technol. Lett. 23, 1085-1087 (2013)

Yeh, C. H., Chow, C. W., Wang, C. H., Shih, F. Y., Wu, Y. F., Chi, S.: Using four wavelengthmultiplexed self-seeding Fabry-Perot lasers for 10 Gbps upstream traffic in TDM-PON. Opt. Express. $16,18857-18862$ (2008) 
Shih, F. Y., Yeh, C. H., Chow, C. W., Wang, C. H., Chi, S.: Utilization of self-injection Fabry-Perot laser diode for long-reach WDM-PON. Opt. Fiber Technol. 16, 46-49 (2010)

Yeh, C. H., Chow, C. W., Liu, Y. L.: Adaptive upstream optical power adjustment depending on required power budget in PON access. Opt. Commun. 285, 4927-4930 (2012)

Chow, C.W., Yeh, C.H.: Using downstream DPSK and upstream wavelength-shifted ASK for Rayleigh backscattering mitigation in TDM-PON to WDM-PON migration scheme. IEEE Photonics J. 5, 7900407 (2013)

Dong, Z., Chien, H. C., Yu, J., Zhang, J., Cheng, L., Chang, G. K.: Very-high throughput coherent ultradense WDM-PON based on Nyquist-ISB modulation. IEEE Photonics Technol. Lett. 27, 763-766 (2015)

Zhu, M., Zhang, L., Fan, S. H., Su, C., Gu, G., Chang, G.K.: Efficient delivery of integrated wired and wireless services in UDWDM-RoF-PON coherent access network. IEEE Photon. Technol. Lett. 24, $1127-1129$ (2013)

Yi, L., Li, Z., Bi, M., Wei, W., Hu, W.: Symmetric 40-Gb/s TWDM-PON with 39-dB power budget. IEEE Photon. Technol. Lett. 25, 644-647 (2013)

Taguchi, K., Asaka, K., Kimura, S., Suzuki, K. I., Otaka, A.: Reverse bias voltage controlled burstmode booster SOA in $\lambda$ tunable ONU transmitter for high-split-number TWDM-PON. J. Opt. Commun. Netw. 10, 431-439 (2018)

Mandal, G. C., Patra, A. S.: High capacity hybrid WDM/TDMPON employing fiber-to-the-home for triple-play services with 128 ONUs. J. Opt. 46, 347-351 (2017)

Li C. Y., Lu, H. H., Lin, C. Y., Chu, C. A., Chen, B. R., Lin, H. H., and Wu, C. J.: Fiber-wireless and fiber-IVLLC convergences based on MZM-OEO based BLS. IEEE Photonics J. 8, (2016). DOI: 10.1109/JPHOT.2016.2538967

Yu, J., Huang, M. F., Qian, D., Chen, L., Chang, G. K.: Centralized lightwave WDM-PON employing 16-QAM intensity modulated OFDM downstream and OOK modulated upstream signals. IEEE Photonics Technol. Lett. 20, 1545-1547 (2008)

Khalighi, M. A., Uysal, M.: Survey on free space optical communication: a communication theory perspective. IEEE Commun. Survey Tuts. 16, 2231-2258 (2014)

Chaman-Motlagh, A., Ahmadi, V., Ghassemlooy, Z.: A modified model of the atmospheric effect on the performance of FSO links employing single and multiple receivers. J. Modern Opt. 57, 37-42 (2010)

Kani, J.: Enabling technologies for future scalable and flexible WDM-PON and WDM/TDM-PON systems. IEEE J. Sel. Topics Quantum Electron. 16, 1290-1297 (2010)

Xu, Z., Wen, Y. J., Zhong, W. D., Chae, C. J., Cheng, X. F., Wang, Y., Lu, C., Shankar J.: Highspeed WDM-PON using CW injection-locked Fabry-Perot laser diodes. Opt. Exp. 15, 2953-2962 (2007)

Cho, K. Y., Hong, U. H., Suzuki, M. Chung, Y. C.: 103-Gb/s long-reach WDM PON implemented by using directly modulated RSOAs. IEEE Photon. Technol. Lett. 24, 2011-2013 (2012)

Nguyen, Q.T., Bramerie, L., Besnard, P., Shen, A., Garreau, A., Kazmierski, C., Duan, G.H., Simon, J.C.: 24 channels colorless WDM-PON with L-band10Gb/s downstream and C-band $2.5 \mathrm{~Gb} / \mathrm{s}$ upstream using multiple- wavelengths seeding sources based on mode-locked lasers. Proc. Int. Conf. Opt. Fiber Commun. OSA Th5C.3 (2010)

Cheng, M., Tsai, C., Chi, Y., Lin, G. R.: Direct QAM-OFDM encoding of an L-band master-to-slave injection-locked WRC-FPLD pair for $28 \times 20 \mathrm{~Gb} / \mathrm{s}$ DWDM-PON transmission. J. Lightw. Technol. 32, 2981-2988 (2014) 
Cheng, X., Wen, Y. J., Dong, Y., Xu, Z., Shao, X., Wang, Y., Lu, C.: Optimization of spectrum-sliced ASE source for injection-locking a Fabry-Perot laser diode. IEEE Photon. Technol. Lett. 18, 19611963 (2006)

Kemal, J. N., Marin-Palomo, P., Panapakkam, V., Trocha, P., Wolf, S., Merghem, K., Lelarge, F., Ramdane, A., Randel, S., Freude, W., and Koos, C.: WDM transmission using quantum-dash modelocked laser diodes as multi-wavelength source and local oscillator, Proc. Int. Conf. Opt. Fiber Commun. OSA paper no. Th3F.6. (2017). https://doi.org/10.1364/OFC.2017.Th3F.6

Cano, I., Omela, M., Prat, J., Poggiolini, P.: Colorless $10 \mathrm{~Gb} / \mathrm{s}$ extended reach WDM PON with low BW RSOA using MLSE. OFC/NFOEC. (2010). https://doi/ 10.1364/ofc.2010.owg2

Parolari, P., Marazzi, L., Brunero, M., Martinelli, M., Brenot, R., Maho, A., Barbet, S., Gavioli, G., Simon, G., Saliou, F., Chanclou, P.: 10-Gb/s Operation of a colorless self-seeded transmitter over more than $70 \mathrm{~km}$ of SSMF. J. Lightw. Technol. 26, 599-602 (2014)

Feng, Q., Li, W., Zheng, Q., Han, J., Xiao, J., He, Z., Luo, M., Yang, Q., Yu, S.: Impacts of backscattering noises on upstream signals in full duplex bidirectional PONs. Opt. Exp. 23, 1557515586 (2015)

Yoshida, T., Kimura, S., Kimura, H., Kumozaki, K., Imai, T.: A New Single-Fiber 10-Gb/s Optical Loopback Method Using Phase Modulation for WDM Optical Access Networks. J. Lightw. Technol. 24, 786-796 (2006)

Chow, C. W., Talli, G., Townsend, P. D.: Rayleigh Noise Reduction in 10-Gb/s DWDM-PONs by Wavelength Detuning and Phase-Modulation-Induced Spectral Broadening. IEEE Photon. Technol. Lett. 19, 423-425 (2007)

Lazaro, J. A., Arellano, C., Polo, V., Prat, J.: Rayleigh Scattering Reduction by Means of Optical Frequency Dithering in Passive Optical Networks with Remotely Seeded ONUs. Photon. Technol. Lett. 19, 64-66 (2007)

Yeh, C. H., Chow, C. W., Huang, S. P., Sung, J. Y., Liu, Y. L., Pan, C. L.: Ring-based WDM access network providing both Rayleigh backscattering noise mitigation and fiber-fault protection. J. Lightwave Technol. 30, 3211-3218 (2012)

Chiuchiarelli, A., Proietti, R., Presi, M., Choudhury, P., Contestabile, G., Ciaramella, E.: Symmetric $10 \mathrm{Gbit} / \mathrm{s}$ WDM-PON based on cross-wavelength reuse to avoid Rayleigh backscattering and maximise band usage. Electron. Lett. 45, 1343 (2009)

Choudhury, P. K.: Enhanced noise tolerance for 10Gb/s Bi-directional cross-wavelength reuse colorless WDM-PON by using spectrally shaped OFDM signals. Opt. Fiber Technol. 42, 6-10 (2018)

Ledentsov, N. N., Grundmann, M., Heinrichsdorff, F., Bimberg, D., Ustinov, V. M., Zhukov, A. E., Maximov, M. V., Alferov, Zh. I., Lott, J. A.: Quantum-Dot Heterostructure Lasers. IEEE J. Sel. Topics Quantum Electron. 6, 439-451 (2000)

Lelarge, F., Dagens, B., Renaudier, J., Brenot, R., Accard, A., Dijk, F., Make, D., Gouezigou, O. L., Provost, J. G., Poingt, F., Landreau, J., Drisse, O., Derouin, E., Rousseau, B., Pommereau, F., Duan, G. H.: Recent advances on InAs/InP quantum dash based semiconductor lasers and optical amplifiers operating at $1.55 \mu \mathrm{m}$. IEEE J. Sel. Top. Quantum Electron. 13, 111-124 (2007)

Bimberg, D., Kirstaedter, N., Ledentsov, N. N., Alferov, Zh. I., Kopev, P. S., Ustinov, V. M.: InGaAs-GaAs quantum-dot lasers. IEEE J. Sel. Topics Quantum Electron. 3, 196-205 (1997)

Sugawara, M., Mukai, K., Nakata, Y., Otsubo, K., Ishilkawa, H.: Performance and physics of quantum-dot lasers with self-assembled columnarshaped and $1.3-\mu \mathrm{m}$ emitting InGaAs quantum dots. IEEE J. Sel. Topics Quantum Electron. 6, 462-474 (2000) 
Reithmaier J. P., Forchel, A.: Single-mode distributed feedback and micro lasers based on quantumdot material. IEEE J. Sel. Topics Quantum Electron. 8, 1035-1044 (2002)

Rosales, R.: InAs/InP quantum dash mode locked lasers for optical communications. IPRM. (2012). http://dx.doi.org/10.1109/ICIPRM.2012.6403353

Mandal, G. C., Mukherjee, R., Das, B., Patra, A. S.: A full-duplex WDM hybrid fiber-wired/fiberwireless/fiber-VLC/fiber-IVLC transmission system based on a self-injection locked quantum dash laser and a RSOA. Optics Communications 427, 202-208 (2018)

Shemis, M. A., Ragheb, A. M., Khan, M. T. A., Fathallah, H. A., Alshebeili, S., Qureshi, K. K., Khan, M. Z. M.: L-band quantum-dash self-injection locked multiwavelength laser source for future WDM access networks. IEEE Photonics J. 9, (2017). DOI:10.1109/JPHOT.2017.2733162

Montgomery, R., DeSalvo R.: A Novel Technique for Double Sideband Suppressed Carrier Modulation of Optical Fields. IEEE Photon. Technol. Lett. 7, 434-436 (1995)

Mallick, K., Mandal, P., Mandal, G. C., Mukherjee, R., Das, B., Patra, A. S.: Hybrid MMW over fiber/OFDM-FSO transmission system based on doublet lens scheme and POLMUX technique. Optical fiber technol. 52, (2019). DOI:10.1016/j.yofte.2019.101942

Simatupang, J. W., Lin, S. C.: A Study on Rayleigh Backscattering Noise in Single Fiber Transmission PON. International Journal of Innovative Research in Technology \& Science. 4, 11-15 (2016) 


\section{Figures}

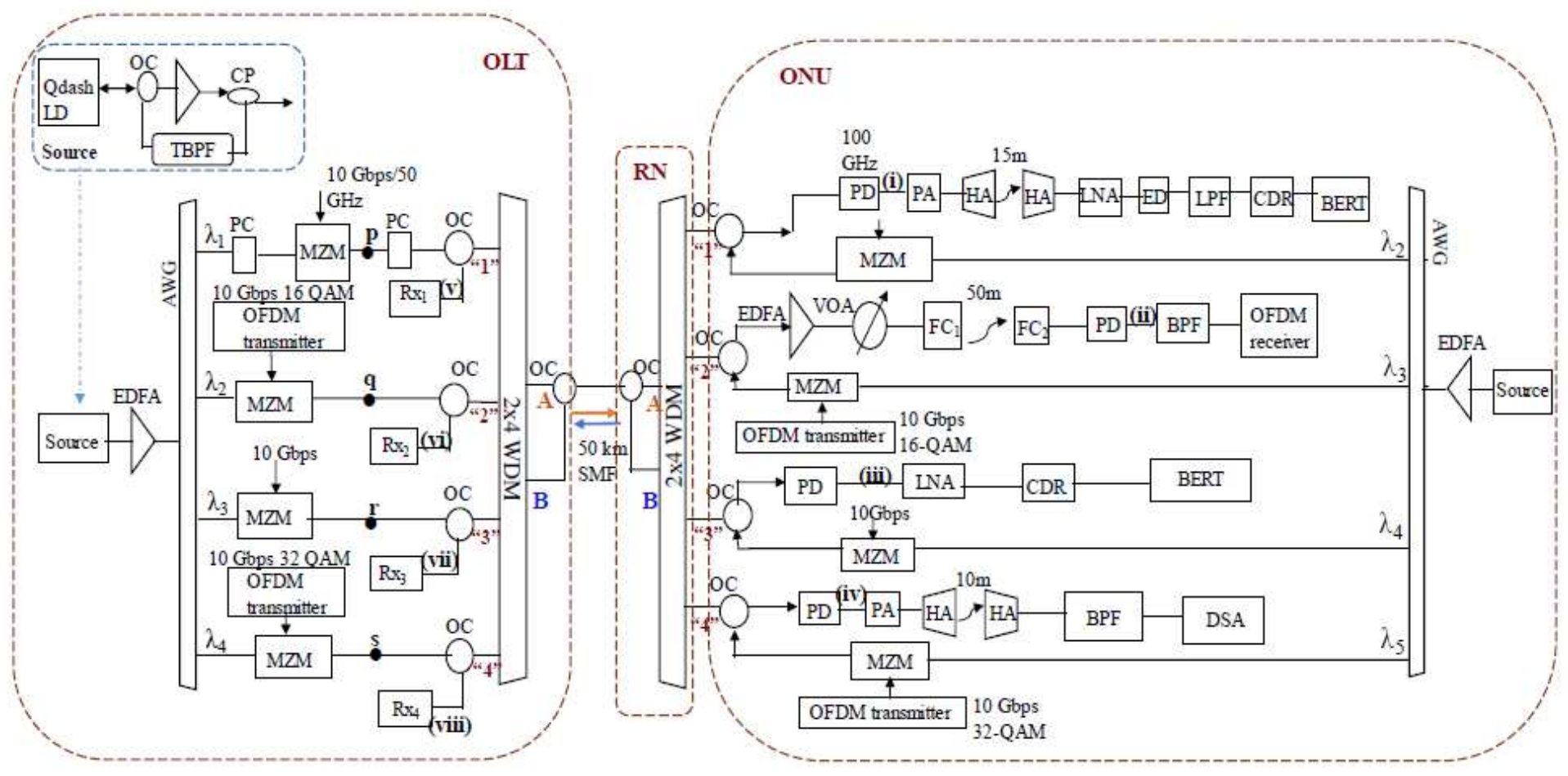

Figure 1

block diagram of proposed bidirectional hybrid WDM-OFDM network for transportation of Rayleigh Backscattering noise eliminated information for multiservice communication by employing a selfinjection locked Qdash laser source.

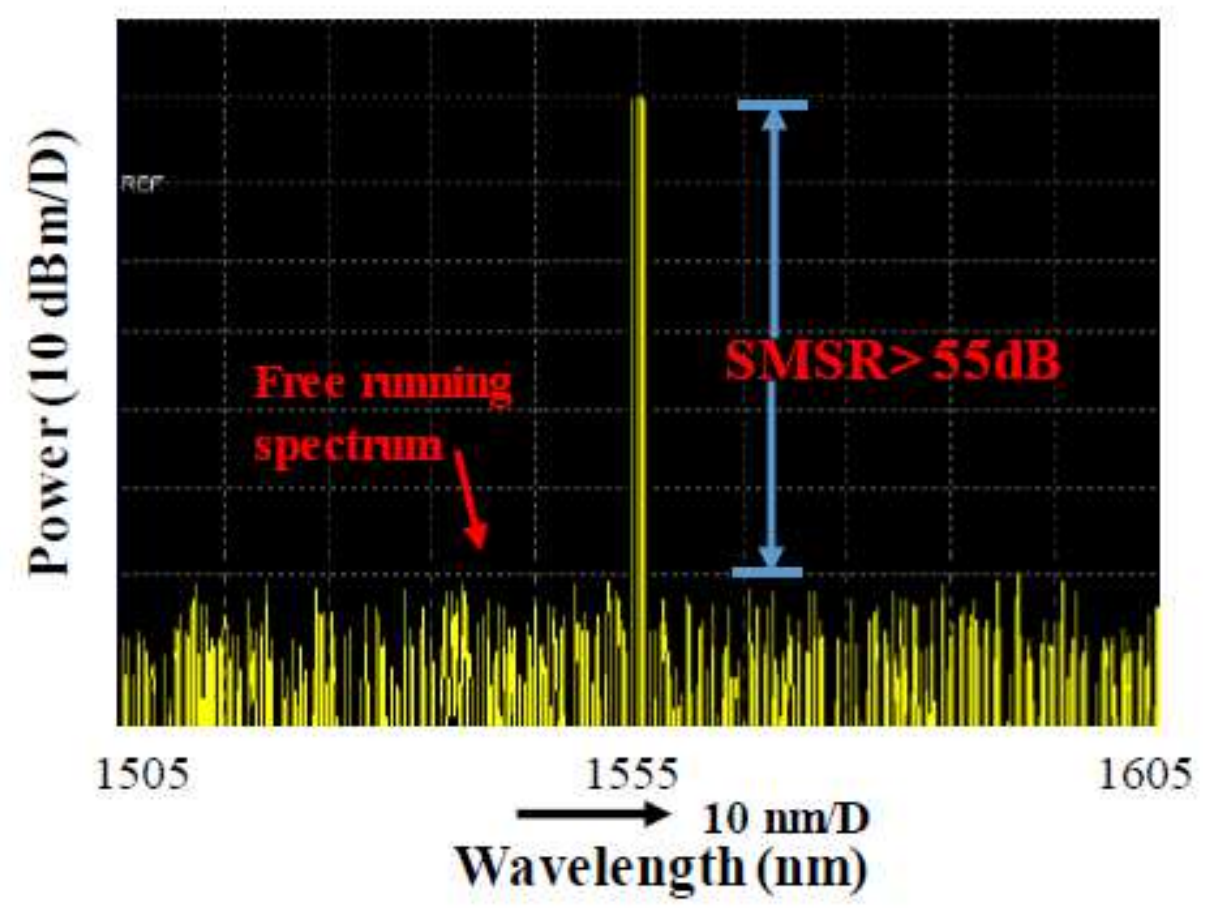

Figure 2 
five self-injection locked modes of Qdash laser.
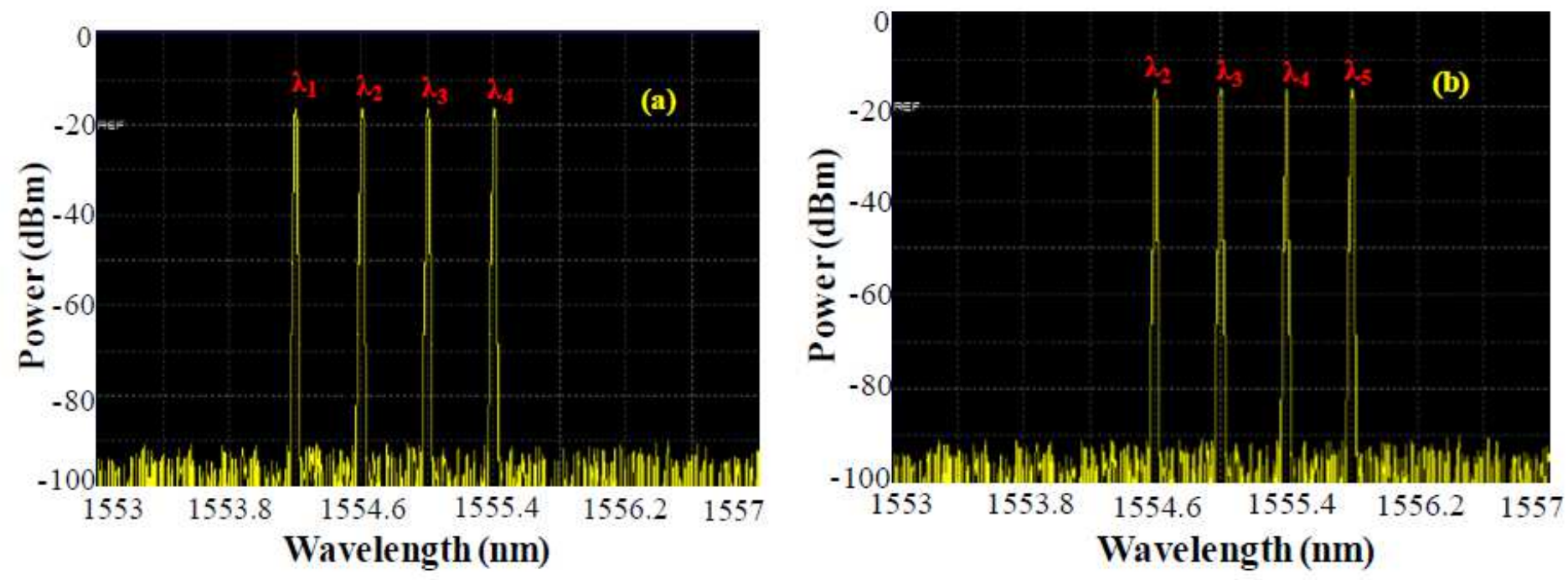

Figure 3

(a). carrier signals for modulation of data for DS transmission (b). carrier signals for modulation of data for US transmission 

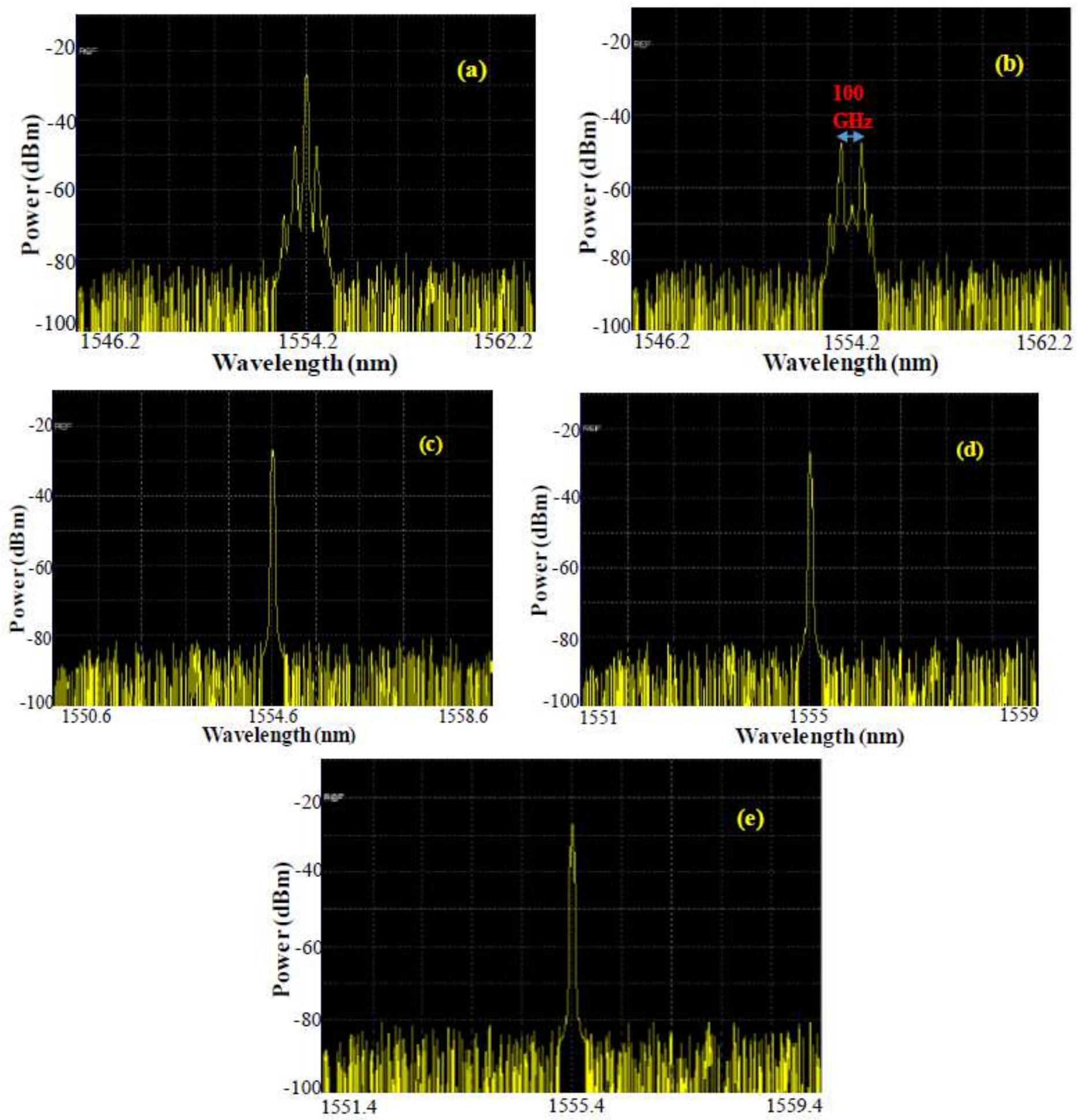

Figure 4

optical spectrum of (a) $10 \mathrm{Gbps} / 100 \mathrm{GHz}$ modulated signal with carrier frequency and (b)-(e) at the output 

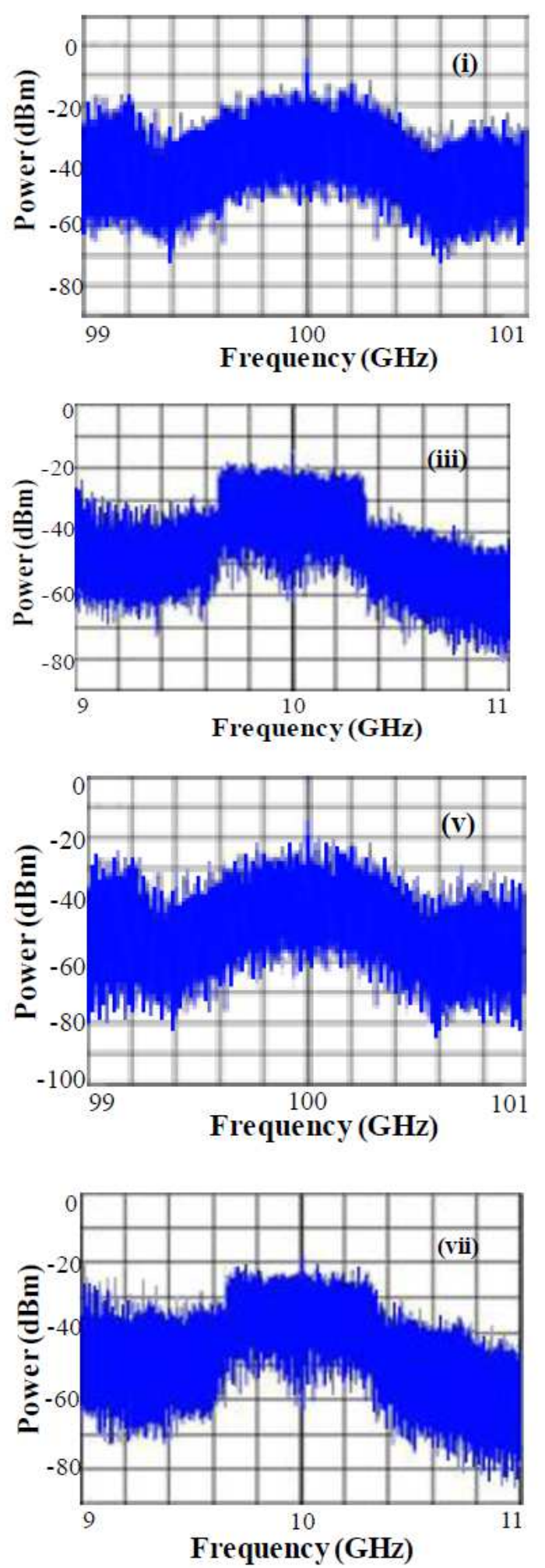
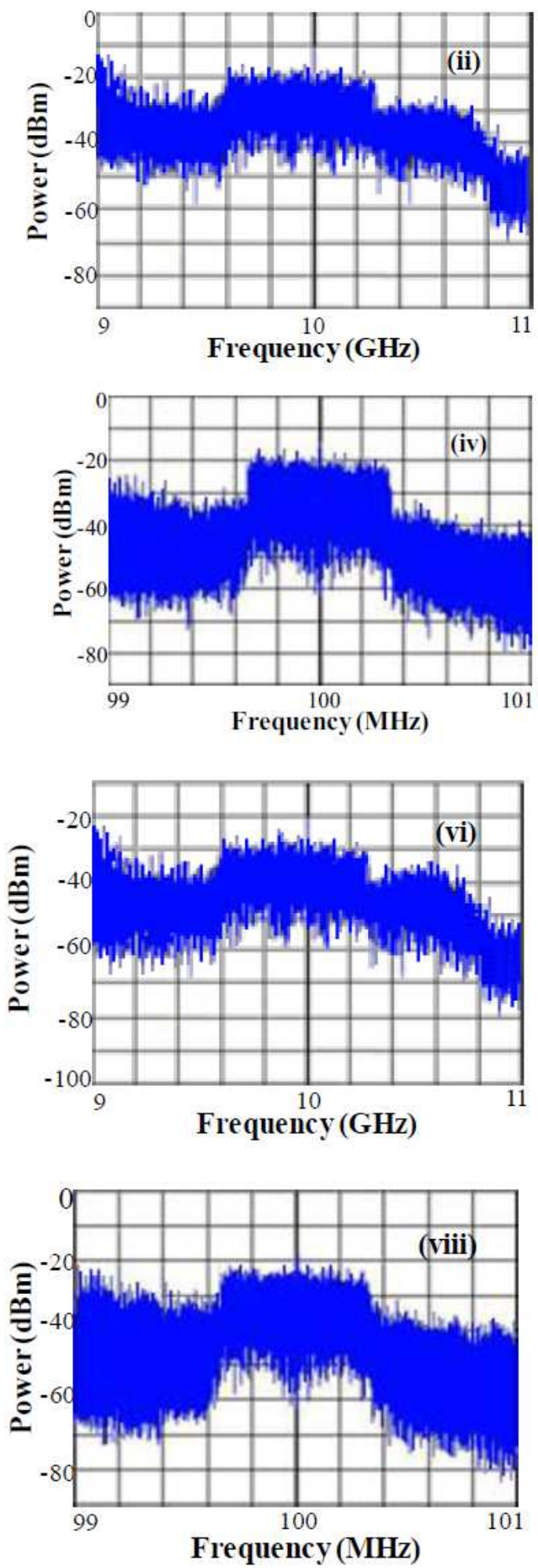

Figure 5

(i)-(viii) Electrical spectra at some important points of electrical path [insert (i)-(viii) of fig.1] 


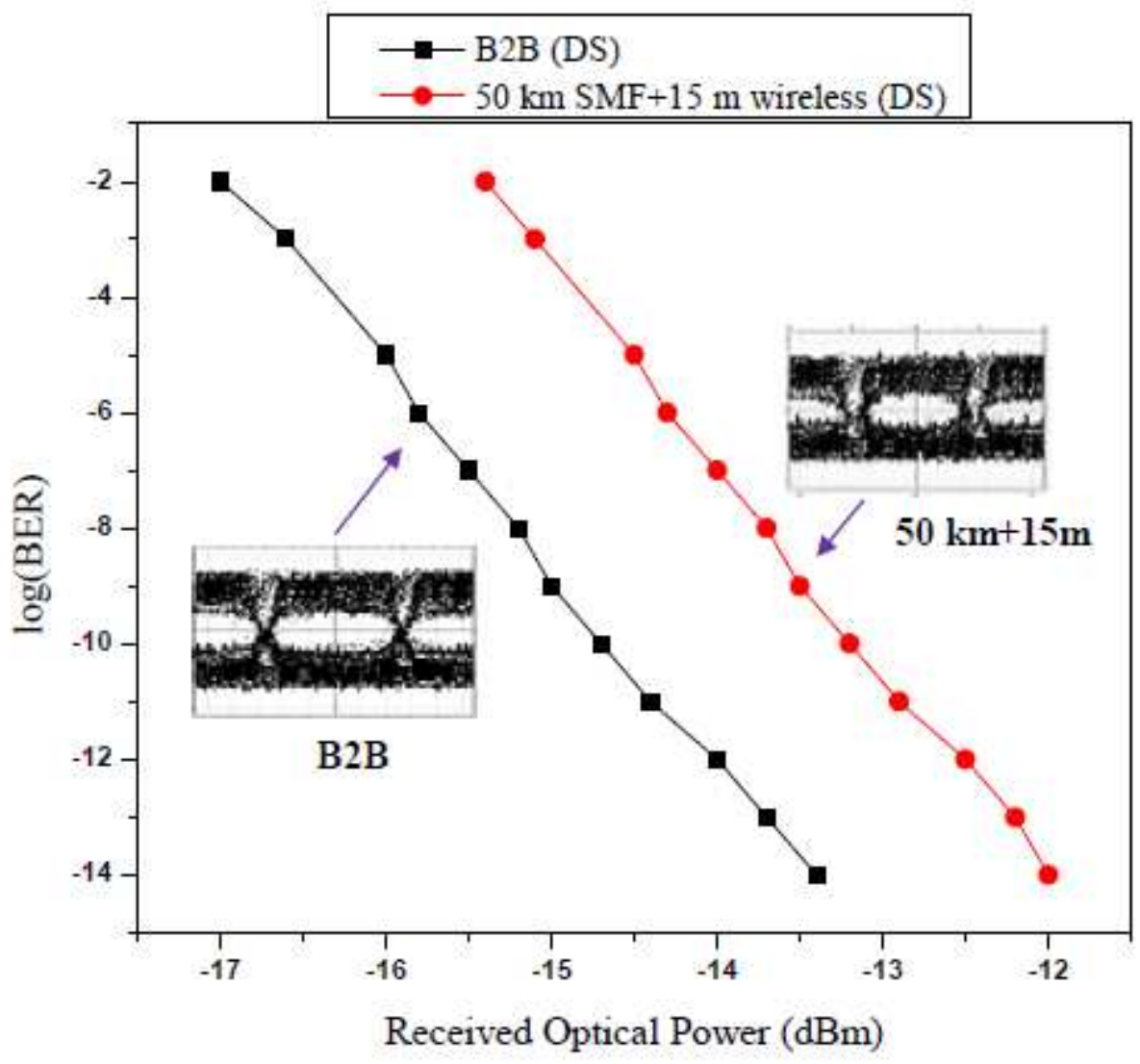

Figure 6

$\log (\mathrm{BER})$ values as a function of receiver optical power and eye diagram for $10 \mathrm{Gbps} / 100 \mathrm{GHz} \mathrm{MMW}$ signal. 


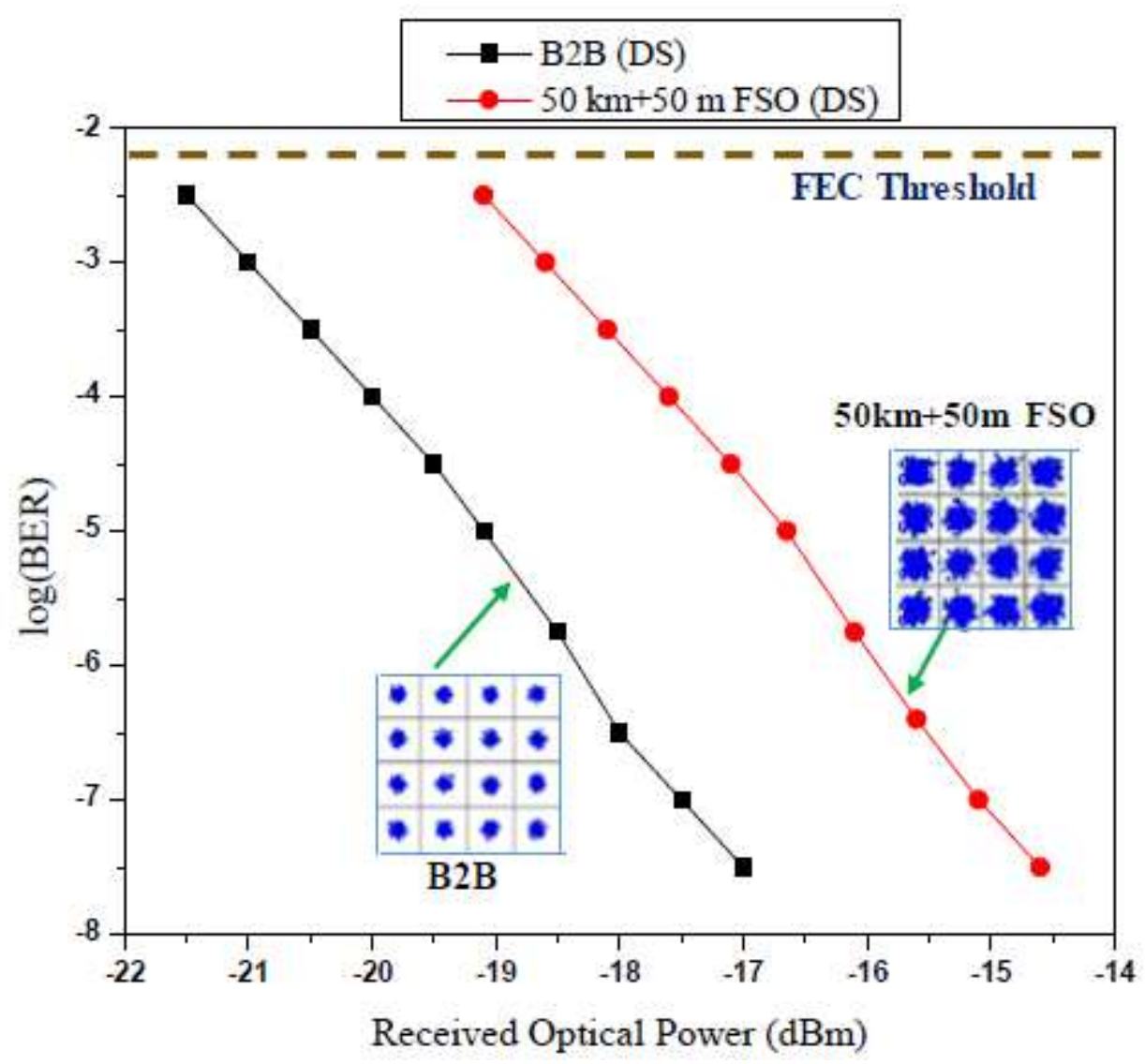

Figure 7

$\log (\mathrm{BER})$ values as a function of receiver optical power and constellation diagrams for 10 Gbps 16 QAM OFDM signal. 


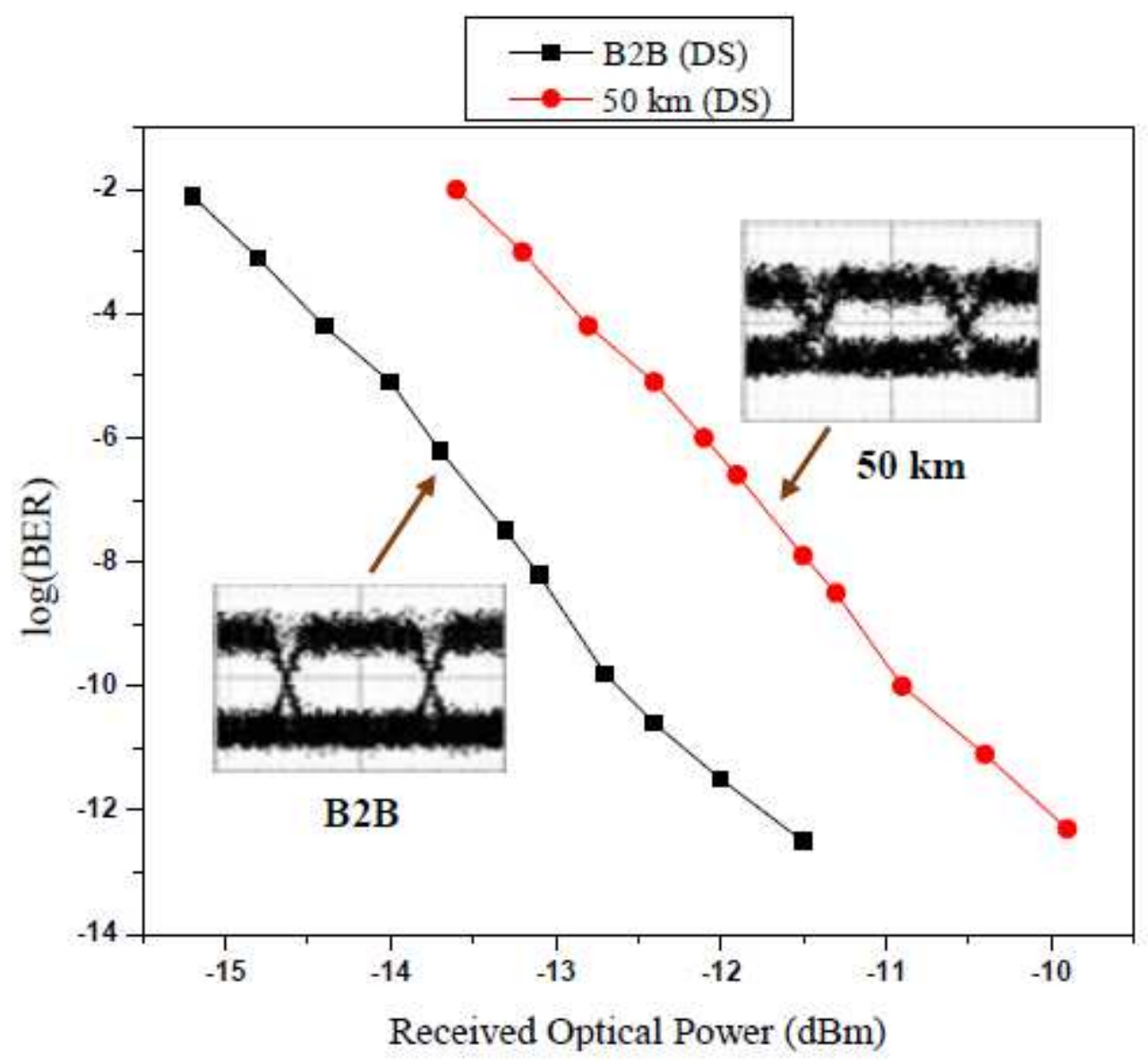

Figure 8

$\log (B E R)$ values as a function of receiver optical power and eye diagram for $10 \mathrm{Gbps}$ BB signal. 


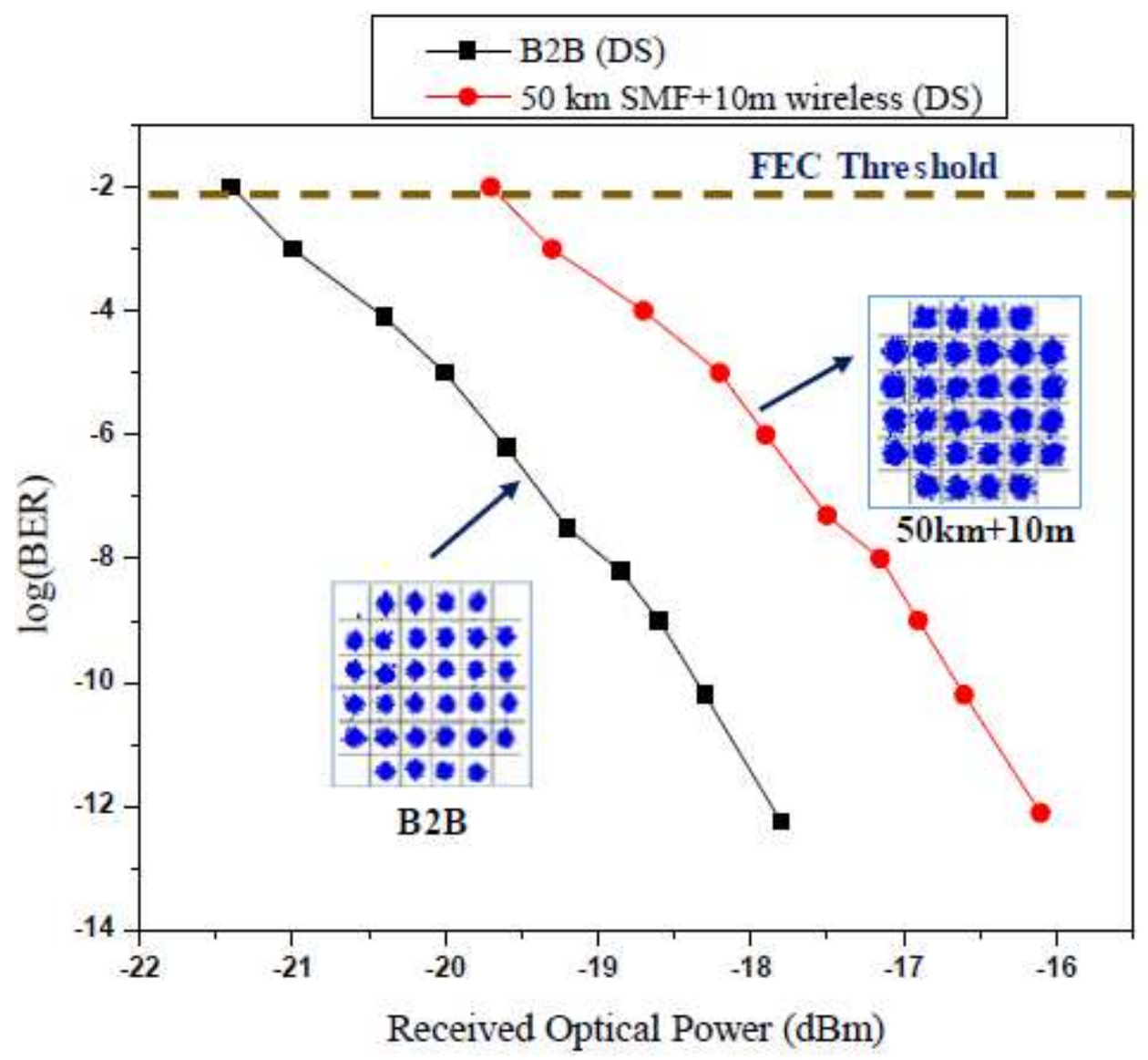

Figure 9

$\log (\mathrm{BER})$ values as a function of receiver optical power and constellation diagrams for $10 \mathrm{Gbps} 32$ QAM OFDM signal. 


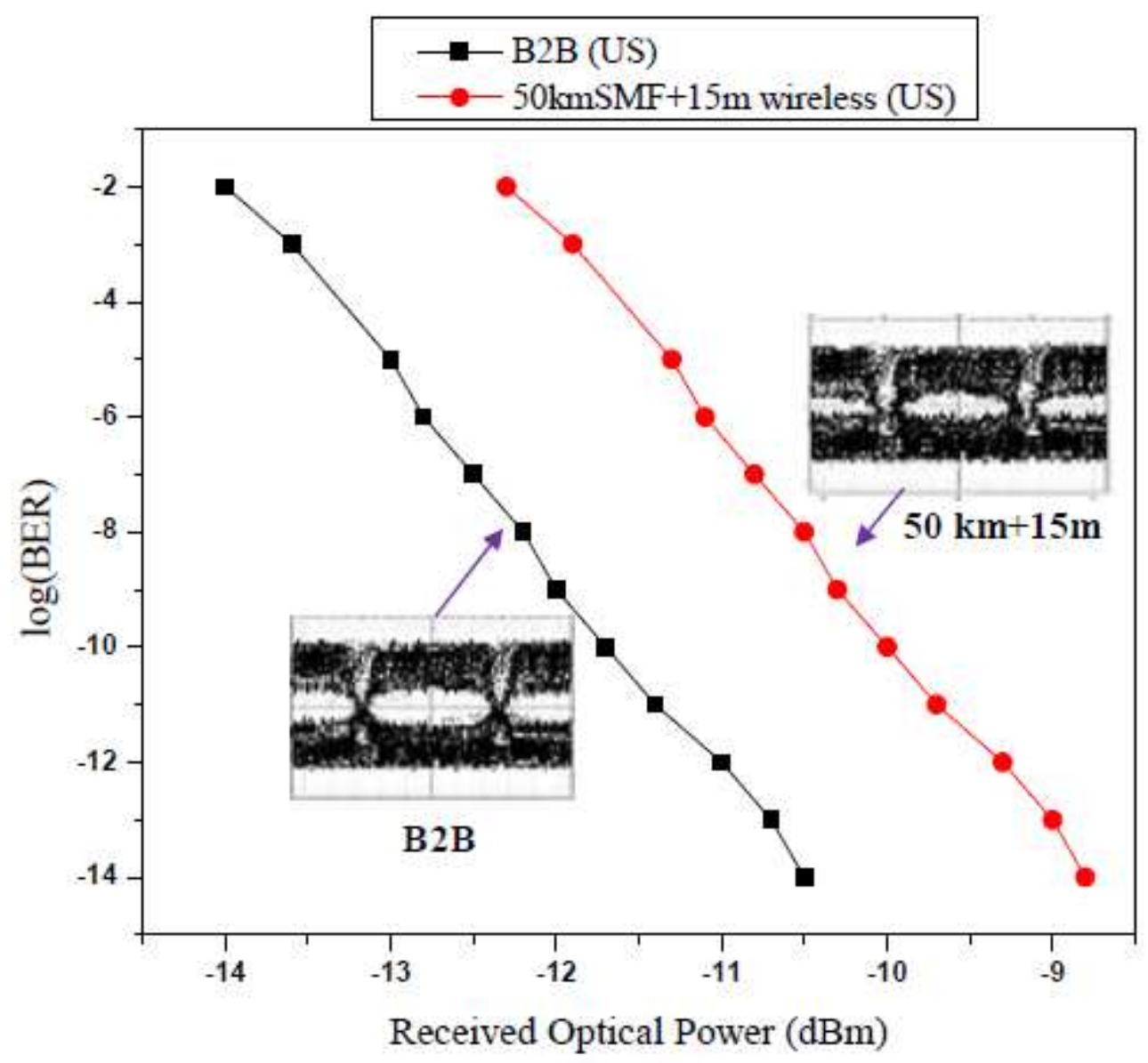

Figure 10

$\log (\mathrm{BER})$ values as a function of receiver optical power and eye diagram for $10 \mathrm{Gbps} / 100 \mathrm{GHz} \mathrm{MMW}$ signal. 


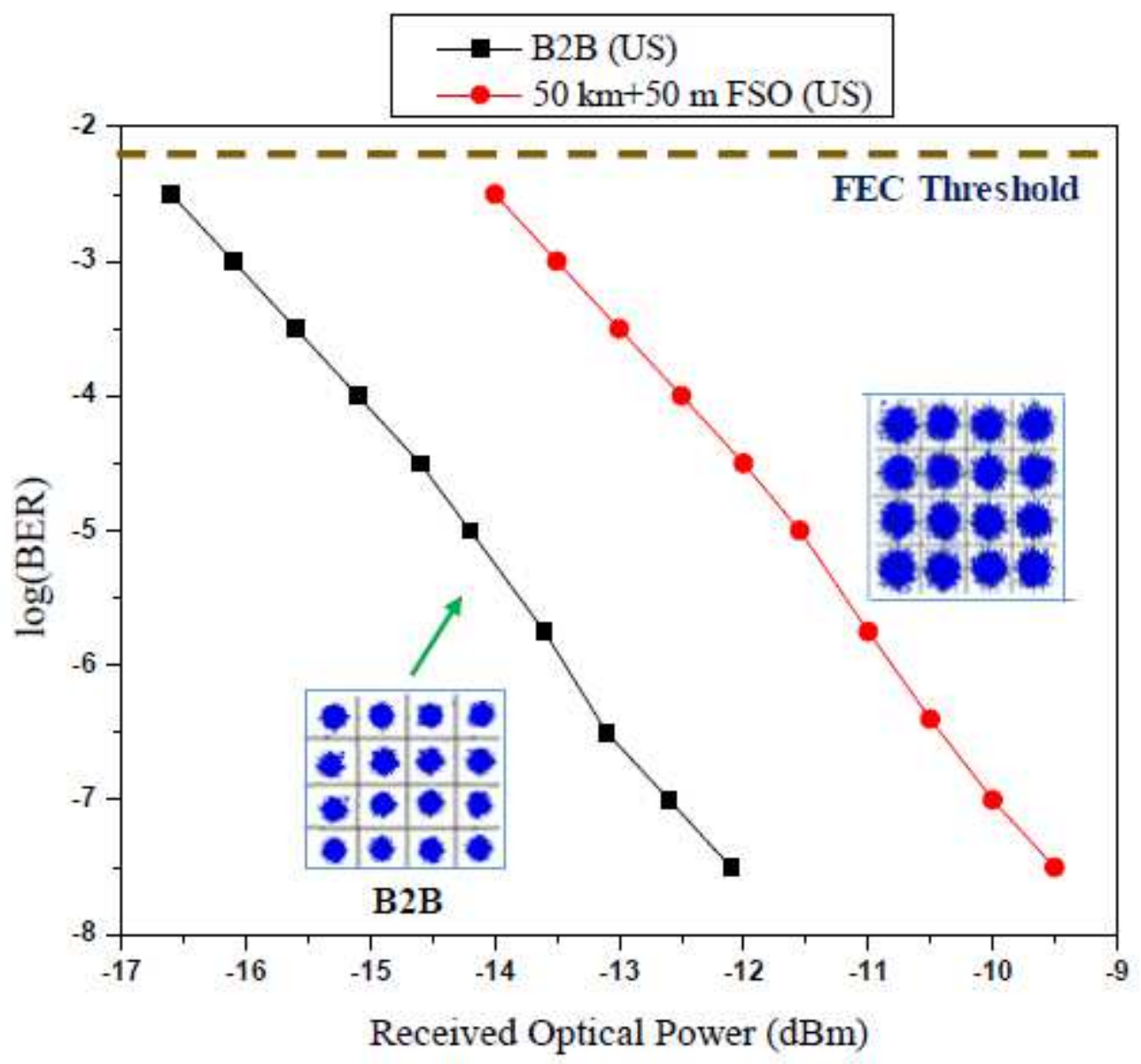

Figure 11

$\log (B E R)$ values as a function of receiver optical power and constellation diagrams for 10 Gbps 16 QAM OFDM signal. 


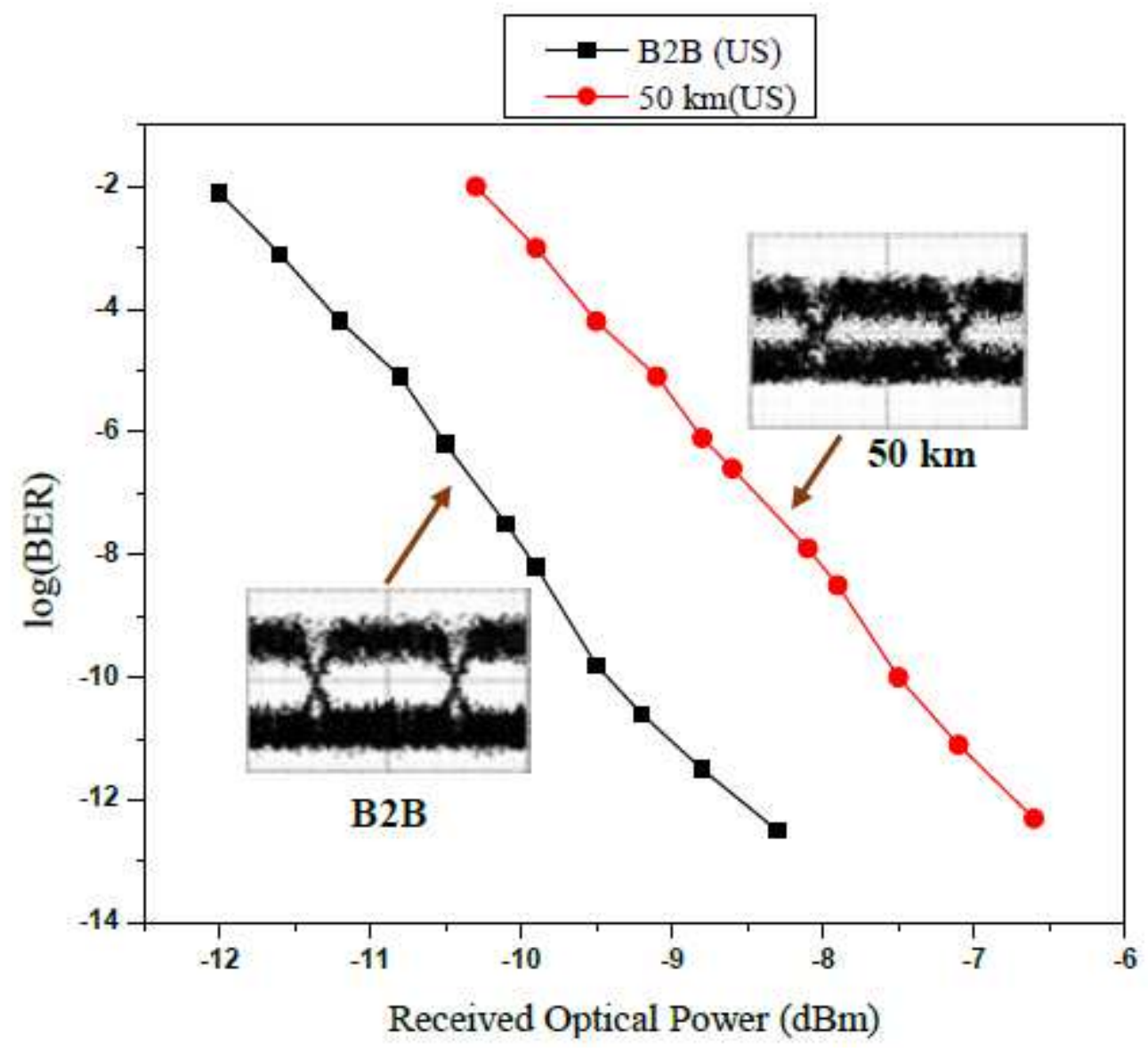

Figure 12

$\log (B E R)$ values as a function of receiver optical power and eye diagram for $10 \mathrm{Gbps}$ BB signal. 


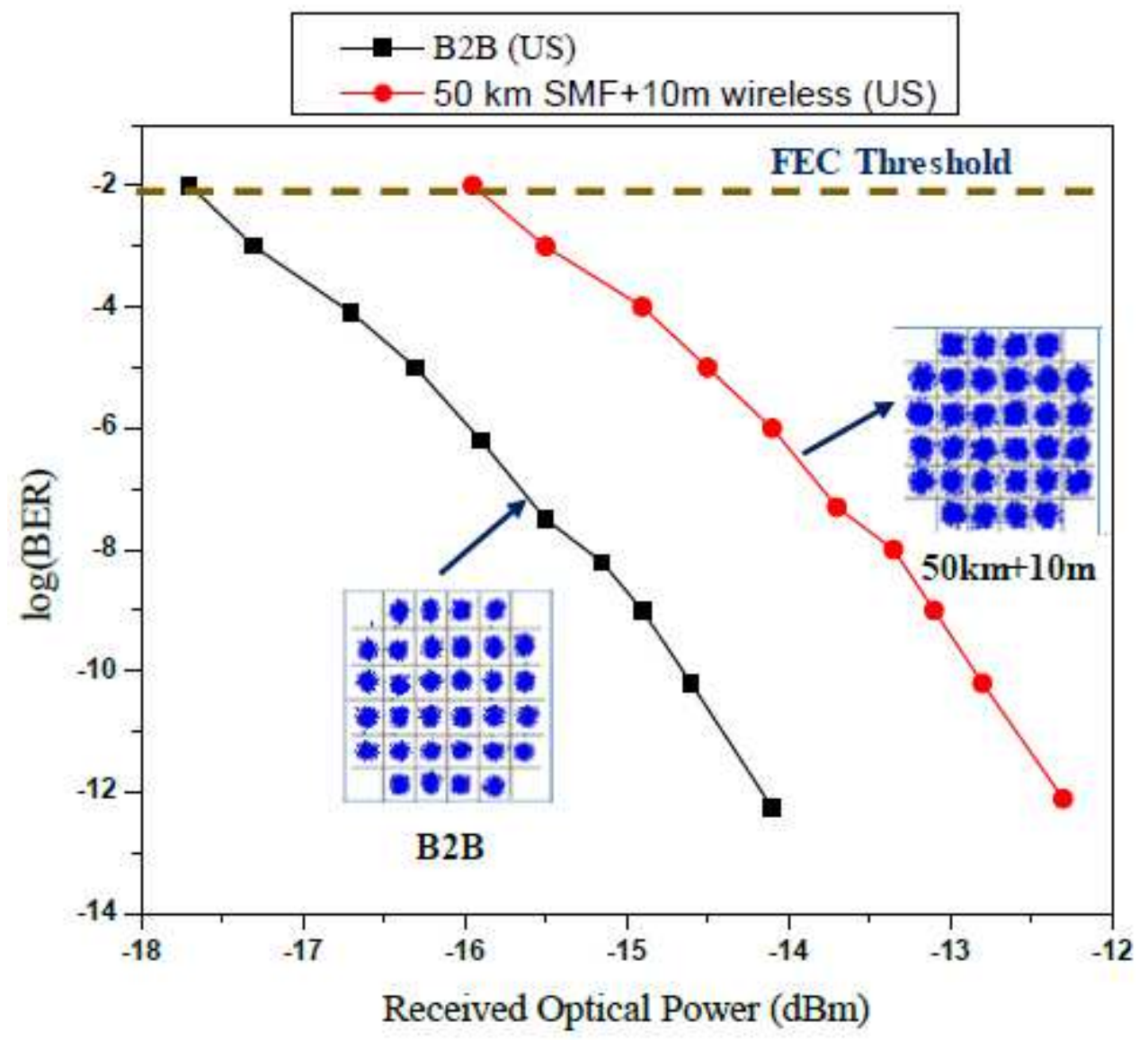

Figure 13

$\log (\mathrm{BER})$ values as a function of receiver optical power and constellation diagrams for $10 \mathrm{Gbps} 32 \mathrm{QAM}$ OFDM signal. 